\title{
The Changing International Network of Sovereign Debt and Financial Institutions*
}

\author{
Mardi Dungey, John Harvey and Vladimir Volkov \\ University of Tasmania, Australia
}

June 2018

\begin{abstract}
We assess the changing nature of the relationships between financial institutions and sovereigns globally using a weighted, directed network of CDS spreads. The framework includes both the strength and direction of the links in the network, allowing us to formally test for evidence on changes in the completeness of the network, for contagion effects, and for strengthening and weakening of the links in the network. We find evidence of all of these effects for 107 US dollar denominated CDS spreads over 2003-2014. We use the results to illustrate the change from a relatively robust network with some vulnerability to financial sector shocks in the pre-GFC period to a highly fragile network during the GFC and a subsequent return to greater robustness post-GFC where, despite the Greek and European debt crisis effects, fragility is similar when sourced from either financial sector or sovereign debt shocks.
\end{abstract}

Keywords: network, sovereign debt, financial institutions, systemic risk, contagion

JEL classification: G01, C58, C31

(c) 2018. This manuscript version is made available under the CC-BY-NC-ND 4.0 license http://creativecommons.org/licenses/by-nc-nd/4.0/

https://doi.org/10.1016/j.intfin.2018.12.013

* CIFR Grant E102. We would like to thank the reviewers and editor of the journal and the following people for useful discussions and comments, Serge Drarolles, Christian Gourieroux, Gaelle Le Fol, Fabio Parlapiano, Loriana Pelizzon, Hashem Pesaran, Daniella Scida, Peter Rozenkranz, Filip Zikes and participants at the ADB/UNSW international conference on financial cycles, systemic risk, and policy options for resiliance, Sydney 2016. Part of this paper was completed while Dungey was Hallsworth Fellow at the University of Manchester and she is grateful for their hospitality. Corresponding author: Mardi Dungey, School of Economics and Finance, University of Tasmania, Private Bag 85, Hobart, Tasmania 7001, Austalia. E-mail: mardi.dungey@utas.edu.au. 


\section{Introduction}

International connections between financial instiutions and sovereign debt markets are important for financial and economic stability. Following the banking and sovereign crises in Europe over 2008-2012 considerable attention has been applied to avoiding future crisis conditions in these markets by better regulation and oversight of financial institutions and a thorough understanding of the role of sovereign debt, including for example calls for non-zero risk weightings on sovereign debt in bank capital assessment; see Hannoun (2011) and Korte and Steffen (2017). Discussion over the root cause of the crisis led to discourse on the diabolic loop (Brunnermeier et al, 2016) where crises spread between the public and private debt sectors of economies as mutually reinforcing problems and the potential of bidirectional links (Acharya et al, 2014a). Podstawaski and Velinov (2018) provide an overview of the taxonomy of the proposed linkage mechanisms between the two sectors. The empirical evidence for the influence of crisis conditions passing within and between the two sectors is growing rapidly, including for cross-border transmissions (Kalbaska and Gatowski, 2012; Alter and Schuler, 2012; Ureche-Rangau and Burietz, 2013; de Bruyckere et al., 2013; Black et al., 2016; Betza et al., 2016; Buch et al., 2016, Kallestrup et al. 2016). The less well-established aspects of these transmissions are their relative importance in different market conditions, whether it is possible to detect building vulnerability to shocks from either source market, and how they contribute to the fragility of an existing financial network.

This paper develops an empirical framework for analyzing the network of connections between financial institutions and sovereign debt, focusing on evidence of changes in the network structure during periods of market stress. The framework provides a mechanism by which 'robust-but-fragile' networks may emerge in the face of an unexpected shock to the system through the financial sector (which we label poor investment decisions) and/or from the sovereign sector (which we label as poor government policies). It differs from the existing literature in examining the changing nature of the networks of interconnections 
over different phases, thus controlling for different volatility regimes (an advance on de Bruyckere et al., 2013) and includes a weighted directed network, improving on the unweighted approach of Billio et al. (2012) and the weighted approach of Diebold and Yilmaz $(2014,2016)$ which includes insignificant linkages.

We provide evidence on three specific hypotheses regarding the changing nature of a global network comprising 67 financial sector institutions and 40 sovereigns via the CDS market over the period 2003 - 2013. Specifically, our framework provides evidence for (i) changes in network completeness weighted by the strength of linkages, combining information on the existence of linkages and their relative importance; (ii) changes in the number of connections between nodes and their strength, consistent with existing tests of contagion; and (iii) the structure of the network and how it evolves under different scenarios. We test for potential changes in the network from September 15, 2008, consistent with the global financial crisis initiated by the collapse of Lehman Brothers, and from April 1, 2010, consistent with the period of the Greek and subsequent sovereign debt crises in Europe.

Our evidence supports a high degree of network completeness, consistent with the major role played by common factors in Longstaff et al. (2011). The empirical framework is based on a network of edges assessed by Granger causality tests as in Billio et al. (2012) and Merton et al. (2013). Drawing on Diebold and Yilmaz $(2009,2014,2016)$ and weighting the existence of linkages by their strength, we show that financial network completeness falls, consistent with Atil et al. (2016) and Fabozzi et al. (2016). The number of links and the completeness of the network incorporating financial institutions and sovereigns may increase across certain crises, as in Billio et al. (2012), Billio et al. (2016), or fall, as in Caporin et al. (2018). Net declines in network completeness may, for example, represent the removal of a large number of weaker linkages and their replacement with a small number of stronger linkages, resulting in differences in network topology between periods. This is important because policymakers may wish to react quite differently to a larger, more loosely connected network than to a more concentrated strongly connected one; see, for example, the literature 
on bank concentration during crises, Beck et al. (2006).

Our approach nests tests for contagion in a systemic risk assessment through the removal and formation of new linkages during periods of financial stress. Contagion is defined as the formation of new linkages, such as new commonalities between formerly unrelated assets, (Dungey and Renault, 2018; Bekaert et al., 2014; Dungey and Martin, 2007), or the breakdown of linkages between counterparties (Gai and Kapadia, 2010) and differences in the transmission mechanisms for tail-shocks,(Boyson et al., 2010; Busetti and Harvey, 2011). By using the Granger causality framework, we are methodologically associated with the contagion literature (Longstaff, 2010; Marais and Bates, 2006; Sander and Kleimeier, 2003). ${ }^{1}$

Evidence of changes in the network structure around the timing of the global financial crisis supports shifts in relationships between financial institutions and sovereign debt markets. One form of these shifts is consistent with both a global flight from markets with heavily increased risk during the crisis - notably source markets from European sovereigns and US financial institutions - represented by the breakdown of network linkages. The other form represents seeking new markets, consistent with a shift in relative risk/return trade-offs globally - notably increased linkages with Africa - represented by the formation of new links in the network.

To examine the issue of the resilience of the network to shocks, and a guage of whether it is robust or fragile, we calculate the expected number of defaults for the network in different sample phases in response to shocks from the banking and/or the sovereign debt sectors. To capture these channels we explore four different scenarios. The first is the benchmark Good times when the network does not encounter any shocks from either source. When both sovereign and financial sectors experience stress simultaneously then economic outcomes are

\footnotetext{
${ }^{1}$ Acemoglu et al. (2015) use the term contagion to denote the transmission of shocks across their networks based on the known lending relationships between banks. Their usage is more consistent with spillovers, where spillovers are ex ante known linkages between nodes; contagion is usually used to refer to transmission of shocks beyond that indicated by the usual linkages. For an overview, see Dungey et al. (2005).
} 
expected to be worse, and we dub this as the stress scenario. Sovereign debt stress can be a source of defaults for not only other sovereigns but also the financial sector. We examine this through a Poor government channel for shocks from sovereigns to the rest of the network. Similarly, Poor investment decisions resulting in shocks from the financial sector may transmit stress to the sovereign sector.

We examine the robustness and fragility of the network when exposed to the four combinations of shocks and during different phases of network evolution. In particular, we look at what the implication is for the number of defaults in response to a poor outcome in one or both markets when the network represents relatively calm decisions, when it is already under stress, and when it is in a recovery phase. We find that the network is indeed more fragile when confronted by shocks from both sectors. However, the nature of this fragility changes with the different phases. In the calm, pre-crisis period, the benchmark expected number of defaults is relatively low, but a 3 standard deviation shock in both sovereign and banking sectors increases this to almost one quarter of the nodes, and is dominated by the response to banking sector shocks, sovereign debt shocks play a minor role in the fragility of the network. In the GFC period the stress scenario results in the default of almost all nodes in the network when the shock is sufficiently high. Both the banking and sovereigns are important sources pointing towards the existence of a diabolic loop. In the post-GFC period the network settles again where the expected number of defaults absent shocks is similar to that of the pre-crisis period. However, a major difference is evident in the fragility of the network via financial institutions. In the third phase the financial institutions contribute to fragility at a rate which has reduced to be marginally less than that of the sovereign debt sector. The evidence clearly supports that the fragility in the pre-crisis financial network was firmly located in the banking sector.

The paper proceeds as follows. Section 2 discusses the motivation and related empirical hypotheses for analyzing empirically a network incorporating financial institutions (banks), real economy firms, and sovereign debt. Section 3 explores 
the data set used for empirical analysis. The econometric methodology for establishing edges is outlined in Section 4, and Section 5 presents results for our sample of 107 entities (financial institutions and sovereigns), and Section 6 provides the analysis of network robustness and fragility in response to shocks sourced in either sector. Section 7 concludes.

\section{Motivation and hypotheses development}

Theoretical network models for the transmission of shocks between banks can be found in Gai and Kapadia (2010) and Acemoglu et al. (2015). In these frameworks banks are in the business of lending for projects with uncertain returns and, as in Diamond (1982) banks cannot fund their lending activities from their own balance sheets and need to engage in inter-bank relationships. This creates networks of liabilities between banks, where the edges are determined by repayments required between pairs of financial institutions. Banking networks become highly interconnected as banks can hold assets and liabilities with any number of other banks in the network, as in Allen and Babus (2009).

The empirical evidence supports that banks may also experience crises induced by sovereign debt market conditions, and that sovereign debt market conditions may reflect crises originating in financial institutions; see for example Acharya et al. (2014a). The existing literature hypothesises that the transmission of crisis conditions between financial institutions and sovereign debt may occur via a number of possible channels. A number of alternative naming conventions exist for the channels of transmission between sovereign debt and financial markets, or sometimes equivalently between private and public credit provision, Podstawski and Velinov (2018) provide a recent review. Brunnermeier et al. (2016) coined the term diabolic loop to capture the case when these channels become mutually reinforcing.

The basis of much of the transmission of stress between financial institutions and the sovereign debt sector stems from the relatively large holdings of sovereign debt by financial institutions, and the (implicit or explicit) guarantees 
governments offer financial institutions to ensure financial stability. Financial institutions will be negatively effected by any decline in the value of the sovereign debt assets, triggering balance sheet effects and encouraging them to deleverage their private credit provision. This channel is referred to as the collateral channel (Podstawski and Velinov, 2018) or portfolio channel (Buch et al., 2016). A reduction in sovereign debt ratings can bring about a similar effect (Arezki et al, 2011). In addition to these balance sheet effects, stress in the sovereign debt sector may also lead to concerns about the ability of the government sector to withstand and fund calls for support from the financial sector, effectively decreasing the insurance value they provide via the guarantee channel (Alter and Schuler, 2012, Kallestrup et al., 2016).

Government influence on the behaviour of financial institutions also forms a possible channel for transmission of crises from sovereigns. When a government either has substantial ownership (perhaps through nationalisation) or influence over financial institutions it may use moral suasion to encourage financial institutions to invest strategically in the sovereign debt of the stressed nation. In this way the financial sector becomes more exposed to the stricken public debt sector, providing a potential means of a worsening spiral. This channel may contribute to increased evidence of home bias, where the financial institution becomes more exposed to the domestic problems and/or to risk shifting between the sectors. Acharya and Steffen (2015) combine moral suasion, home bias and risk shifting under the heading of a carry-trade channel, where it essentially captures the case of taking on more risk in hope of increased payoff to improve the longer term situation. Both Altavia, Pagano, Manganelli (2017) and Onega, Popov and van Horen (2016) distinguishing carry trade (as risk shifting) from moral suasion and provide empirical evidence supporting its existence. Altavia et al. (2017) find that banks which are public or have been recently rescued are more likely to be subject to moral suasion.

A further channel from sovereigns to the financial sector exists via macroeconomic policy decisions. Unsustainable macroeconomic policy actions will be reflected in the risk of sovereign debt which results in risk transfer to the finan- 
cial sector. Jorda et al. (2016) finds little historical evidence that developed markets have crises that are preceded by bad fiscal policy as the precipitating condition (they exclude emerging markets), but does confirm that poor public debt situations prior to crisis events result in longer and deeper recessions than otherwise. They argue that the evidence strongly supports private credit markets as the source of crisis events. See also the historical overview of Reinhart and Rogoff (2009).

The sovereign debt sector may also receive stress from stressed financial institutions who seek a greater proportion of safe assets via the collateral channel. The safety net channel describes the implicit guarantees provided by sovereigns to financial institutions. When financial institutions are under stress this creates a link to the sovereign bond markets via the option on government support which is priced into the equity value, and hence balance sheet, of the financial institutions. Financial institutions will buy government debt in order to meet their prudential targets (Brunnermeier et al., 2016). Concerns about the need to fund bailouts will pressure the debt sustainability of the public sector. As balance sheets of the private lending sector contract this will lead to contraction of credit in the economy and cetirus paribus, reduced economic activity and less government revenue to meet ongoing fiscal obligations (Kallestrup et al., 2016, Alter and Schuler, 2012).

When a diabolic loop is established, and financial sector crises and sovereign debt crises coincide, the outcomes for economies are disproportionately worse than when faced with only one source of crisis. Altavia, Pagano, Manganelli (2017) find that stressed banks which face sovereign debt stress have significantly larger cuts in lending. It is well known that dual crisis recessions are more severe than those where only one market is affected. Most existing analyses do not specifically investigate the role of transmission across national borders between banking and sovereign debt markets, see Arezki et al. (2011) for an exception. However, this is a source of further concern, prompting the formation of more forums for cross-national regulatory co-operation, and proposals for Sovereign Bond-Backed Securities, such as European Safe Bonds (ESBies), to distribute 
the flight of funds during crises more evenly across national borders, as discussed in Brunnermeier et al. (2016) and Brunnermeier et al. (2017).

Our empirical framework links these channels of transmission with network theory via the funds that banks choose not to invest in private sector opportunities. In models such as Acemoglu et al. (2015) these uninvested funds are considered equivalent to a sovereign bond bearing a certain return with no risk. These networks model risks to banks via the uncertain outcomes of their private sector investment decisions. However, as outlined risks may also occur via the sovereign bond market, see also Buch et al. (2016). In this case the values of returns on investment projects and/or sovereign bonds are influenced by an external negative shock as in Glasserman and Young (2015). This shock impacts the network and an entity defaults if it is not able to meet its obligations. In this case, the magnitude of a shock impacts the default probability of an entity and its obligations, potentially increasing the default probability of other entities. The default probability also depends on the volatility of shock that nonlinearly affects the network.

The default risk captured by the balance sheet variables of financial institutions is reflected in CDS spreads (Chiaramonte and Casu, 2012). We use variance decompositions to capture the impacts of shocks on the CDS spreads, relating our methodological framework to the approach of Diebold and Yilmaz (2014). The existence of links between entities is established from Granger causality tests as in Billio et al. (2012). The completeness of the network is characterized by both the number of links between entities and by the corresponding weights. Hypothesis 1 distinguishes whether networks are in fact more intertwined during periods of stress due to the number of linkages or its strength. Moreover, in order to better understand the nature of the crisis we differentiate between weak and strong links (Hypothesis 2).

Hypothesis 1 The completeness of the weighted network decreases during stressful periods due to co-movements of the level and variance of the CDS spreads.

Hypothesis 2 During the crisis periods weaker links are formed and stronger 
links removed in the combined network of sovereigns and financial institutions.

The default probability of an entity characterized by a CDS spread varies according to a shock hitting the network. This allows us to identify different states of nature dependent on the source of the shocks. In good (or normal) times, banks and sovereigns will achieve standard returns; in a poor outcome period both produce lower than expected payoff. In this case, there are four separate potential scenarios that the entity network may face when attempting to meet its liabilities.

Good times: Investments by the financial sector achieve payoff and there are no haircuts in sovereign debt markets. Financial institution networks should function normally - all sources of income are available to meet liabilities.

Stress: There is a shock from the financial sector via poor performance in private investments coinciding with a poor performance shock in the sovereign debt market. A financial institution's incoming counterparty payments needs to exceed outside obligations owing due to the investment, the institution's own outgoing counterparty requirements, private investment losses, and reduced value of the sovereign debt.

Poor investment: Financial institutions suffer a negative shock via investments which do not perform, however, sovereign debt markets perform normally. Bond holdings and incoming counterparty payments need to exceed outside obligations owed, the financial institution's own counterparty requirements, and the loss due to the poor investment outcome.

Poor government: Financial institution private investments perform well, but there is a negative shock from the sovereign debt market. A financial institution's income from successful investments and incoming counterparty payments needs to exceed outside obligations due to the investment, the institution's outgoing counterparty requirements, and the loss on sovereign bonds.

These scenarios identify conditions by which we can assess network robustness and fragility. By subjecting our estimated network to shocks originating from either sovereign debt or financial institutions we examine whether the 
combined network is highly interconnected, with a robust-yet-fragile structure, as proposed by Haldane (2009). Such a network is at risk when exposed to a large enough single shock, or sufficiently proximate contemporaneous small shocks. A robust network will be relatively immune to even large shocks from either source. A fragile network may have a large number of node failures (defaults) in response to even relatively smaller shocks. The scenarios illustrate how combinations of events in private investment and sovereign debt markets may place additional stress on existing banking networks. We establish that the networks between sovereign debt and financial institutions change across our sample period, and use the scenario analysis during different phases to assess the robustness and fragility of the network in response to shocks.

There is likely to be less heterogeneity in sovereign debt market investment opportunities available to the financial sector institutions than in private sector investments. That is, although the failure of a relatively small private investment opportunity can cascade and cause financial stress (Acemoglu et al., 2015) there are in practice fewer sovereign bond investment opportunities. Thus, a shock in the sovereign debt market is likely to cause a simultaneous common shock to a number of entities, providing a further means of amplifying a crisis via the network. Both the stochastic shock and its variance are important quantities that impact both sovereign and bank returns and may cause cascades of defaults in the network.

\section{Data and Summary Statistics}

Modeling the interconnections between financial institutions is hampered by data availability. On the one hand, many of the theoretical frameworks are expressed in terms of inter-entity flows, such as Cabellero (2015). However, these data are exceedingly difficult to obtain, particularly outside the official family; a good example is the UK interbank network in Giraitis et al. (2016), who use data available to the Bank of England. On the other hand, there is a strand of literature that takes advantage of market-based data as proxies to develop an 
understanding of the interconnectedness of networks, as in, for example, Merton et al. (2013). Van de Leur and Lucas (2017) finds that the interconnectedness networks based on market data produce valuable information that is not offered by alternative approaches. The work in this paper draws on the market-based data tradition in this literature.

Five-year CDSs are the most commonly issued and traded asset in this class and are the most liquid (Bouri et al. 2017; Duca and Peltonen 2013; Kalbaska and Gatkowsi 2012; Pan and Singleton 2008); data on these contracts were extracted from Markit over the period from January 1, 2003, to November 21, $2013 .^{2}$ Over the full period, there are 2842 end-of-day CDS spread prices for each sovereign and institution. The combined dataset contains 40 individual sovereigns and 67 institutions, for a total of 107 nodes used in the analysis, as listed in Tables 1 and 2 .

The sample is divided into three separate phases; Phase 1 represents the non-crisis period from January 1, 2003, to September 14, 2008. This is typical of dating conventions used to separate the pre-crisis and crisis periods; see the review of dates extant in the literature in Dungey et al. (2015). Phase 2 represents the period from September 15, 2008, to March 31, 2010, consistent with the global financial crisis (GFC) and period following. The end of March 2010 represents the period prior to which the Greek debt crisis became critical in April 2010. Phase 3, from April 1, 2010, to November 21, 2013, represents the post-GFC period which includes the Greek and European sovereign debt crises.

The first panel of Table 3 shows summary statistics for Phase 1 . Phase 1 is the longest of the three exogenously chosen time periods, containing 1488 observations per entity. Latin America displays a higher mean spread during Phase 1, while financial institutions and insurance companies exhibit relatively higher kurtosis than other groups.

\footnotetext{
${ }^{2}$ Unfortunately suitable updates to the database are not available because much of the activity in this market has moved to other assets than the USD denominated issues selected for this study, which seems to reflect changes in supervisory arrangements favoring domestic currency issuance.
} 
The GFC period, Phase 2, is the shortest of the sub-sample phases, with 403 observations per entity. There is an increase in spread means for most groups of institutions and sovereigns, reflecting the perceived increase in risk during this turbulent period in international debt markets. The financial institution group has the largest mean, standard deviation and kurtosis during Phase 2.

The third phase, associated with the post-GFC period including the Greek debt crisis and subsequent European debt crisis, involves a small decline in spread means; however the Eurozone group's mean spreads increase from Phase 2, potentially due to the transformation of the Greek debt crisis into the European debt crises during the third phase. Insurance companies and Latin American sovereigns exhibit high levels of kurtosis compared with other groups.

The CDS spreads were found to be non-stationary, I(1), with a maximum of one unit root according to KPSS and ADF tests. Moreover, the presence of heteroskedasticity in daily spreads was confirmed by applying Breusch-Pagan and White tests.

To control for exogenous common factors ${ }^{3}$ we use a combination of the global indexes: the West Texas Intermediate US dollar based international index for crude oil prices, the VIX index regarded as a standard measure of investors' risk aversion, and the MSCI world index capturing performance of the global stock market.

\section{Econometric Framework}

\subsection{Estimating the approximating network model}

To take into consideration the common stochastic trend(s) between the I(1) CDS series and the potential impact of exogenous global factors, a Vector Error Correction Model (VECM) is specified as follows:

$$
\Delta Y_{t}=\mathrm{Exo}_{t}+\Pi_{0} Y_{t-1}+\sum_{j=1}^{k-1} \Gamma_{j} \Delta Y_{t-j}+\varepsilon_{t},
$$

\footnotetext{
${ }^{3}$ An importance of taking into account exogenous global factors has been also emphasized by Alter and Beyer (2014).
} 
where $Y_{t}=\left[Y_{1, t}, \ldots, Y_{n, t}\right]^{\prime}, \Delta Y_{t-j}=Y_{t-j}-Y_{t-j-1}$, Exo $t$ is a set of exogenous variables in first differences, and $\Pi_{0}, \Gamma$ are the parameters of the model. ${ }^{4}$ The VECM model defined in (1) needs to be estimable in high dimension, $n=107$, and for this reason we follow Demirer et al (2018) using LASSO techniques. ${ }^{5}$ While Demirer et al. (2018) applied the LASSO method to stationary I(0) data to estimate a VAR the present paper deals with I(1) variables requiring a VECM estimation. We follow Liao and Phillips (2015), and adopt the automated estimation of the VECM defined in (1) which enables simultaneous estimation of the cointegrating matrix $\Pi_{0}$ and the transient parameters $\Gamma_{j}$. Specifically, the LASSO-type estimator of $\Pi_{0}$ and $\Gamma_{0}=\left[\Gamma_{1}, \ldots, \Gamma_{k-1}\right]$ is defined as

$$
\begin{aligned}
\left(\hat{\Pi}_{0}, \hat{\Gamma}_{0}\right) & =\underset{\Pi_{0}, \Gamma_{1}, \ldots, \Gamma_{k-1}}{\operatorname{argmin}}\left\{\sum_{t=1}^{T}\left\|\Delta Y_{t}-\operatorname{Exo}_{t}-\Pi_{0} Y_{t-1}-\sum_{j=1}^{k-1} \Gamma_{j} \Delta Y_{t-j}\right\|^{2}\right. \\
& \left.+T \lambda \sum_{j=1}^{k-1}\left\|\Gamma_{j}\right\|+T \lambda\left\|\Pi_{0}\right\|\right\}
\end{aligned}
$$

where $\lambda$ is a tuning parameter that directly control the penalization, $\|\cdot\|$ denotes the Euclidean norm. ${ }^{6}$

Given the tuning parameter $\lambda$ the shrinkage estimator $\left(\hat{\Pi}_{0}, \hat{\Gamma}_{0}\right)$ delivers a one step estimator of (1). Parameter $\lambda$ is chosen using cross validation with a lambda-min criterion. A preparatory estimation of the rank of the matrix $\Pi_{0}$ by applying a Johansen test is not required in this case. The parameters of model (1) are used to establish a structure of the network.

\subsection{Establishing network edges via Granger causality}

Financial institutions and sovereign debt issuers form network nodes linked by edges. The use of Granger causality tests on CDS spreads to establish edges

\footnotetext{
${ }^{4} \mathrm{~A}$ constant term is suppressed for simplicity.

${ }^{5}$ LASSO blends shrinkage and selection and proves particularly appealing for large VARs and VECMs. A detailed review of these techniques can be found in Hastie, Tibshirani, and Wainwright (2015).

${ }^{6}$ The LASSO estimator presented in (2) is a simplified version of the LASSO proposed by Liao and Phillips (2015) which works on the rows of the adaptively transformed matrix defined by $\Pi_{0}$. Here we penalize $\Pi_{0}$ directly to reduce the number of tunning parameters.
} 
between nodes has a number of advantages in this framework. It is directly comparable to existing empirical networks of Billio et al. (2012) and Merton et al. (2013). It establishes directional edges, allowing for an examination of the causation from sovereign debt to banking markets. Granger causality established edges map clearly to the existing empirical frameworks for measuring and testing contagion during financial crises via the formation and breaking of linkages (Dungey et al., 2005).

CDS spread data used to motivate the Granger causality testing effectively represent a premium for insurance against the default of a third party. CDS spread prices reflect a perceived risk of default; favorable news decreases the value of the CDS spread, while unfavorable news increases the value. Significant Granger causality from entity $i$ to entity $s$ indicates that $Y_{i}$ has at least one significant lag predicting the value of $Y_{s}$. Thus, perceived risk of entity $i$ defaulting predicts the perceived risk of default of entity $s$. The edges of the network constructed from these Granger causality links represent predictors of each node's perceived risk of default.

Once a VECM in (1) is estimated ${ }^{7}$, it can be represented as a VAR

$$
Y_{t}=\operatorname{Exo}_{t}+\sum_{j=1}^{k} \Phi_{j} Y_{t-j}+\varepsilon_{t},
$$

with cross-equation restrictions $\Phi_{1}=\Pi_{0}+\Gamma_{1}+I_{n}, \Phi_{j}=\Gamma_{j}-\Gamma_{j-1}, j=2,3, \ldots, k$, and where $I_{n}$ is a unit matrix. Granger causality between CDS spreads $Y_{i}$ and $Y_{s}$ can be assessed using the Wald test

$$
W T=[e \cdot \operatorname{vec}(\widehat{\Phi})]^{\prime}\left[e\left(\widehat{V} \otimes\left(Y^{\prime} Y\right)^{-1}\right) e^{\prime}\right]^{-1}[e \cdot \operatorname{vec}(\widehat{\Phi})]
$$

in which $Y$ is the matrix of independent variables from $(3), \operatorname{vec}(\widehat{\Phi})$ denotes the row vectorized coefficients of $\widehat{\Phi}=\left[\Phi_{1}, \ldots, \Phi_{k}\right], \widehat{V}=T^{-1} \sum_{t=1}^{T} \hat{\varepsilon}_{t} \hat{\varepsilon}_{t}^{\prime}$ and $e$ is the

\footnotetext{
${ }^{7}$ The VECM is estimated using two lags. This represents a trade off between optimal lag length criteria and degrees of freedom considerations. A robustness test of the optimal number of lags is discussed in Section 5.3, but the results are largely unaffected by these changes.
} 
$k \times 2(2 k+1)$ selection matrix

$$
e=\left[\begin{array}{cccccccccc}
0 & 1 & 0 & 0 & \ldots & 0 & 0 & \ldots & 0 & 0 \\
0 & 0 & 0 & 1 & \ldots & 0 & 0 & \ldots & 0 & 0 \\
\vdots & \vdots & \vdots & \vdots & \vdots & \ddots & \vdots & \vdots & \vdots & \vdots \\
0 & 0 & 0 & 0 & \ldots & 1 & 0 & \ldots & 0 & 0
\end{array}\right]
$$

Each row of $e$ selects one of the coefficients to set to zero under the non-causal hypothesis $Y_{i} \rightarrow Y_{s}$.

The empirical contagion literature typically focuses on changes in the structure of short-term relationships across two periods. Consider, for example, the first-period interaction matrix estimated for a non-crisis period, denoted $\Phi_{1}^{n c}$, and a crisis period, denoted $\Phi_{1}^{c r}$, as follows:

$$
\begin{aligned}
\Phi_{1}^{n c} & =\left[\begin{array}{ll}
\phi_{i i, 1}^{n c} & \phi_{i s, 1}^{n c} \\
\phi_{s i, 1}^{n c} & \phi_{s s, 1}^{n c}
\end{array}\right], \\
\Phi_{1}^{c r} & =\left[\begin{array}{ll}
\phi_{i i, 1}^{c r} & \phi_{i s, 1}^{c r} \\
\phi_{s i, 1}^{c r} & \phi_{s s, 1}^{c r}
\end{array}\right] .
\end{aligned}
$$

Tests for changes in the network finance literature (and related tests for contagion) can be characterized as tests of whether $\phi_{i s, k}^{n c}=\phi_{i s, k}^{c r}$ and $\phi_{s i, k}^{n c}=\phi_{s i, k}^{c r}$ for all $k$.

In this paper, the focus is on the formation of new links:

$$
\begin{array}{ll}
\text { new link from } Y_{i} \text { to } Y_{s} & H_{0}: \phi_{s i, k}^{j-1}=0 ; \phi_{s i, k}^{j} \neq 0 \\
\text { new link from } Y_{s} \text { to } Y_{i} & H_{0}: \phi_{i s, k}^{j-1}=0 ; \phi_{i s, k}^{j} \neq 0
\end{array}
$$

and the breaking of existing links

$$
\begin{array}{cc}
\text { broken link from } Y_{i} \text { to } Y_{s} & H_{0}: \phi_{s i, k}^{j-1} \neq 0 ; \phi_{s i, k}^{j}=0 \\
\text { broken link from } Y_{s} \text { to } Y_{i} & H_{0}: \phi_{i s, k}^{j-1} \neq 0 ; \phi_{i s, k}^{j}=0
\end{array}
$$

where index $j$ is assigned to each of the three Phases.

The results of the Wald test indicating Granger causality are recorded as binary entries in matrix $A$ as 


$$
A=\left[a_{i s}\right],
$$

where $a_{i s}=0$, if $Y_{i}$ does not Granger cause $Y_{s}$; and $a_{i s}=1$ otherwise. Matrix $A$ is used to construct the directional edges between sovereigns and banks.

\subsection{Network connectedness}

Once linkages between financial institutions and sovereigns, represented by ma$\operatorname{trix} A$ are established, the strength of these linkages can be quantified by assigning weights $W=\left[w_{i j}\right]$ to network edges. ${ }^{8}$ Using the VAR from equation (3) as an approximating model, weights $w_{i j}$ can be obtained from variance decompositions, as proposed by Diebold and Yilmaz (2009). Suppose that $j$ 's contribution to entity $i$ 's $H$-step-ahead orthogonalized forecast error variance, $\theta_{i j}^{o}(H)$, is

$$
\theta_{i j}^{o}(H)=\frac{\sum_{h=0}^{H-1}\left(e_{i}^{\prime} B_{h} P e_{j}\right)^{2}}{\sum_{h=0}^{H-1}\left(e_{i}^{\prime} B_{h} V B_{h}^{\prime} e_{i}\right)}, \quad H=1,2,3, \ldots,
$$

in which $V$ is the variance-covariance matrix for the error vector $\varepsilon_{t}, P$ is the lower triangular matrix obtained from the Cholesky decomposition of $P P^{\prime}=V$, and $e_{i}$ is the selection vector with one as the $i$ th element and zero otherwise. The coefficient matrices, $B_{i}$, obey the recursion $B_{i}=\Phi_{1} B_{i-1}+\Phi_{2} B_{i-2}+\ldots+\Phi_{k} B_{i-k}$, with $B_{0}$ being an $n \times n$ identity matrix and $B_{i}=0$ for $i<0$. Note that the orthogonalized variance decomposition allows for correlated shocks and does depend on the ordering of the variables. ${ }^{9}$

In the original framework of Koop, Pesaran and Potter (1996) and Pesaran and Shin (1998), variance shares do not necessarily sum to 1 , that is, $\sum_{j=1}^{n} \theta_{i j}^{o}(H) \neq 1$. Hence, each entry of the generalized variance decomposition matrix is normalized by the row sum as

$$
w_{i j}=\frac{\theta_{i j}^{o}(H)}{\sum_{j=1}^{n} \theta_{i j}^{o}(H)} .
$$

\footnotetext{
${ }^{8}$ In this case, the network is defined as a weighted directed graph. A weighted financial network is also used by Demirer et al. (2018) and Glasserman and Young (2015) to model connectedness between financial institutions.

${ }^{9}$ The variance decomposition estimates are not sensitive to different orderings as discussed in Section 5.3.
} 
Now, by construction, $\sum_{j=1}^{n} w_{i j}=1$ and $\sum_{i, j=1}^{n} w_{i j}=n$.

Given the estimates of matrix $A$ and weighting matrix ${ }^{10} W=\left[w_{i j}\right]$, the structure of the weighted network can be characterized by matrix

$$
\widetilde{A}=A \odot W,
$$

where $\odot$ is the Hadamard product. Elements of adjacency matrix $\widetilde{A}$ capture the connectedness between institutions and sovereigns conditional on significant casual linkages between them. ${ }^{11}$ The network defined by adjacency matrix $\widetilde{A}$ shows the predictors of the risk of default subject to a shock captured by matrix $W$. Using the entries of matrix $\widetilde{A}$, system-wide completeness is measured as

$$
C=\frac{\sum_{\substack{i, j=1 \\ i \neq j}}^{n} \tilde{a}_{i j}}{\sum_{\substack{i, j=1 \\ i \neq j}}^{n} w_{i j}} .
$$

This measure is used in the following sections to analyze the system-wide connectedness between the financial institutions and sovereigns. ${ }^{12}$

\section{$5 \quad$ Results}

To illustrate the degree of connectivity in the financial network, Figure 1 represents the network of weighted significant Granger causality links between pairs of financial institutions in Phase 1 at the $5 \%$ significance level. ${ }^{13}$ This network is characterized by a node size, node color, edge thickness and edge arrow size. ${ }^{14}$ The node size and the node color indicate the weighted degree of a node (the number of edges that are incident on that node), ranging from

\footnotetext{
${ }^{10}$ Matrix $W$ is not necessarily symmetric, in contrast to the partial correlation network of Anufriev and Panchenko (2015), which is symmetric by construction.

${ }^{11}$ This approach extends the spillover index of Diebold and Yilmaz (2009). While the spillover index contains all elements of a variance decomposition matrix, here, the elements that are not linked causally are equal to zero. The importance of disentangling the network strength from the network structure is also highlighted by Scida (2015) in a different context.

${ }^{12}$ The completeness measure can be computed for sub-networks (e.g., the completeness of a specific geographical region) in the same way by summing up the specific elements $\tilde{a}_{i j}$ and $w_{i j}$.

${ }^{13}$ The results are almost unaffected by more stringent significance levels such as $1 \%$.

${ }^{14}$ The same graphical display is used for all empirical results. The open-source software GEPHI is used to visualize network graphs.
} 
bright (low weighted degree) to dark orange (high weighted degree). Edge thickness and edge arrow sizes indicate pairwise directional connectedness "TO" and "FROM". Following Demirer et al. (2018) we determine node location using the ForceAtlas2 algorithm. This algorithm finds a state in which edges attract the nodes they connect according to average pairwise connectedness, highlighting the entities that are more important in terms of weighted degrees. The financial network, presented in Figure 1, is highly, connected consistent with results in Longstaff et al. (2011), Eichengreen et al. (2012), and Eom and Park (2017). Furthermore, three major insurance companies, AEG, ACE and AIG, are the main spreaders of systemic risk, see also Dungey et al. (2018) for evidence on the importance of US insurers. Due to the difficulty of analyzing highly interconnected nodes visually, we do not present the combined network of financial institutions and sovereigns. In both cases, the degree of connectivity is relatively high - the potential number of links is $67 ! / 65 !=4355)$ links in the financial instiutions network, and 107!/105!(=11342) in the combined network.

\subsection{Financial Institutions network}

To aid analytical tractability, we condense the network shown in Figure 1 to five nodes. The 67 financial institutions in our sample are grouped into institutional types: banks, insurance companies, investment banks, real estate firms, and other financial institutions. The constituents of these groups are shown in Table 1. The dispersion of these institutions by country is not conducive to undertaking a geographic-institutional breakdown; as we are considering institutions involved in the CDS market we make the relatively safe assumption these institutions are globally active investors. ${ }^{15}$ Institutions may invest in almost any sovereign debt market and be involved in cross-border counterparty arrangements and have sophisticated currency hedging mechanisms in place. A potential limitation of our approach is home bias or incomplete currency hedging distorting the results.

\footnotetext{
${ }^{15}$ An analysis of the changing connections between financial institutions in Europe and the US using equity market data may be found in Diebold and Yilmaz (2016), and for global banks in Demirer et al. (2018). Moreover, a number of papers consider the detailed relationships for CDS within these regions. For example, see Fabozzi et al. (2016) for the Eurozone.
} 
Figure 2 presents the same information as Figure 1 using the institutional types as nodes, displaying the same high degree of completeness. The width and shade of the edges indicate the strength of links between two nodes, representing the proportion of significant linkages among potential linkages, as explained in Sections 4.2 and 4.3. Figure 2 illustrates the strength of the links involving banks, financial institutions, and insurance companies, while links to real estate and investment firms are less strong. Arrows on the ends of edges provide evidence on direction of transmission - the results suggest bidirectional linkages. A node size represents importance of an industry in terms of weighted degree.

Formally, Hypothesis 1 is tested by estimating a Jaccard coefficient $(J C)$ that measures similarity between networks in two different phases. This coefficient takes values between 0 and 1 and is normally distributed. If $J C<0.5$ the completeness of the network is different in two phases. Table 4 shows that the the estimated values of $J C$ are all significant and less than 0.5 , indicating that the network in Phase 1 is statistically different from that in Phase 2, and the network in Phase 2 is statistically different from that in Phase 3.

Table 5 documents that 1040 of the 4355 potential links exist in Phase 1, increasing to 1323 in Phase 2, confirming a change in the network topology. Between Phase 1 and Phase 2, the net increase in links is due to the formation of 1024 links, overwhelming the loss of 741 stronger links (the average strength of the new links is 0.0164 compared with that of the removed links of 0.0196). Thus, between Phases 1 and 2, the completeness of the weighted network of financial institutions drops from $41.25 \%$ to $38.33 \%$, primarily through reduced strength of links. Eichengreen et al. (2012), also find that spillovers from US to European banks decrease during the GFC period.

The further removal of 1146 (weaker) links and formation of 386 (stronger) links between Phase 2 and Phase 3 means that the net loss of 760 links results in weighted network completeness falling to $20.00 \%$, primarily due to a decreased number of links. Overall the Phase 3 network has 477 fewer links than Phase 1, and the average strength of links has decreased. This finding points to potential increased fragility of the financial sector during the GFC, consistent with Alter 
and Schuler (2012). Once both the existence and strength of linkages are taken into account, the completeness of the financial network is lower in Phase 2 compared with Phase 1 - which differs from the findings of Diebold and Yilmaz (2016) - and lower still in Phase 3, consistent with Caporin et al. (2018).

Figure 3 illustrates the location and strength of newly formed and removed linkages for each phase. The reduction in links is distributed relatively evenly across banks, financial institutions, and insurance companies in Phase 1 and Phase 2 (Figure 3a). The removal of links between banks and insurance companies is also indirectly observable through a financial channel by unraveling the strong direct connections from banks to financial institutions and from the latter to insurance. This pattern is part of the complex debate surrounding whether insurers were causal in generating the systemic risk of this period (Biggs and Richardson, 2014). An investment channel stayed relatively unchanged between Phase 1 and Phase 2.

Between Phase 2 and Phase 3, there is evidence of strong disconnection between banks and all other entities. Banks and financial institutions are the focus of a substantial number of disconnections during the crisis, and this may reflect new international risk assessments and domestic regulatory environments whereby financial companies are recognized as contributing to systemic risk. However, the removed links from financial companies to insurers highlight the further propagation of systemic risks. Insurers favor self-regulation and insurance as a recipient of shocks from banks, an argument supported in Cummins and Weiss (2014), but in contrast with the view of the Financial Stability Board, and Acharya et al. (2014b), who report that insurers may propagate systemic risk. Real Estate and investment companies are even more disconnected from Banks and Insurance.

As a proportion of total links, there are relatively few new links forming during Phase 2, shown in Figure 3c. As institutions attempt to manage their portfolios, and risk appetite generally decreases, the financial system becomes less interconnected. Regulators around the globe have more carefully monitored financial institutions since 2008, and formed new bodies to address segments of 
the financial sector, which may have been a contributing factor.

\subsection{Combined financial institutions and sovereign debt network}

The combined financial institutions and sovereign network has potentially $\frac{107 !}{105 !}$ $(=11342)$ links. The number of links in Phase 1 is 1734 , increasing to 3737 in Phase 2 and falling to 1297 in Phase 3, as reported in Table 5. As before, the Jaccard statistics reported in Table 4 show that the networks are statistically significantly different between Phases 1, 2 and 3.

The intertwining of these two sectors is relatively incomplete in the pre-crisis period (at $28.28 \%$ ) but rises substantially during the GFC sample. The results also reflect the increases in linkages found by Merton et al. (2013) and Betza et al. (2016). Network link changes seem relatively large but must be seen in the context of total number of links; in total 584 (5.15\% of all possible links) were unchanged in the unweighted network during the sample period and 6455 (56.91\%) links did not exist at any point in the sample. However, between Phase 1 and Phase 2, the network lost 1150 and gained 3153 links, a net gain of 2003.

Hypothesis 2 tests for a change in the average strength of the links formed and lost between Phases using a standard two-sample t-test. The hypothesis of equal strength of formed and removed links between Phases 2 and 3 is rejected at the $5 \%$ level. The average strength of the formed links in the weighted network was 0.0088 , weaker than that of the lost links of 0.0125 . That is, the increased completeness between Phases 1 and 2 is due to the formation of more weaker links in the presence of declining strong links. In the transition from Phase 2 to Phase 3, a further 3303 links, of average strength 0.0092, were lost and 863 formed, of average strength 0.0123. The net loss of 2440 links were of lower average strength than those gained, such that overall the number of links fell, contributing to the decline in weighted network completeness.

Not only do the proportions of links change between phases but the taxonomy of these changes is highly revealing. Categorizing nodes into geographic sovereign debt markets and financial institution types, as in the previous sub- 
section, Figure 4 provides the schematic for links that are broken and formed from Phases 1 to 2, and from Phases 2 to 3 .

The results in Figure 4a show that the CDS premia for insurance companies became disconnected from bank CDS premia during the first crisis phase. There is a concentration of lost connections between the banks and Euro, Europe, Latin America, Asia, and Africa sovereign sector links. The Eurozone's disconnection from Europe and Asia is not evident in the link changes.

Relatively more links are formed between Phase 1 and Phase 2, as shown in Figure 4c. Most pronounced are the new links between banks and Asian and Latin American sovereign bond markets, suggesting an increasing importance of developing markets in global risk determination during this phase. There are also some increases in bank linkages with North American sovereign markets.

During Phase 3, the links previously established between banks and European, Asian and Latin American sovereigns are largely undone, as shown in Figure $4 \mathrm{~b}$. There is less evidence of a retraction of links with financial sector nodes, although the reduction of linkages with financial firms is relatively strong. This is consistent with the findings in Buch et al. (2016) showing reduced links between German banks and sovereign bonds during the European debt crisis. Newly formed links in this phase, as shown in Figure 4d, relate to banks and insurance companies. Further influences on new connections may include asset write-downs, increased premia, regulator scrutiny of sovereign debt exposure, and feedback effects between sovereign debt markets and banks (and, by extension, the financial sector).

The combined network is characterized by highest completeness during crisis Phase 2, originating from banks and financial companies. Moreover, the net number of new links is positive for Phase 2 and negative for Phase 3, consistent with results reported by Diebold and Yilmaz (2014) for the global equity market, and banking-sovereign debt CDS relationships in Betza et al. (2016); both show that system-wide connectedness is higher during the GFC. The difference between our work and existing network papers based on Granger causality is the use of weighted networks, revealing that although the number of unweighted 
links may increase during a crisis, when the links are weighted by their relative strength, the completeness of the network may not decline by as much as in an unweighted system (and in some cases, the weights may be sufficient to induce an increase in network completeness). ${ }^{16}$

\subsection{Specification robustness checks}

We report a number of specification variations and perform a number of robustness checks for our preferred specification.

The lag length choice for the estimated VAR is based on using an AIC and SIC criteria for the model but restricting the choice to the same lag length for each variable. The SIC criterion favors a $\operatorname{VAR}(1)$. The AIC criteria favors a $\operatorname{VAR}(3)$. We choose to implement at $\operatorname{VAR}(2)$ in the body of the paper as a compromise which both retains a higher degree of dynamics and trades off the loss of degrees of freedom with longer lags. Implementation of a $\operatorname{VAR}(3)$ as supported by AIC criteria makes little qualitative difference to the results. Chan-Lau (2017) also finds little sensitivity in network estimation to changing lag length. A $\operatorname{VAR}(2)$ of this dimension has $214 \mathrm{AR}$ parameters to estimate in each equation, putting considerable strain on the data. However, the Cholesky decomposition does allow us to use the residuals from the most exogenous variables as instruments for those of increasing endogeneity - that is the VAR could be estimated on an equation by equation basis equivalently. The smallest sample size is in Phase 2, with 403 observations. This does not leave a great number of degrees of freedom, but adequate in this instance for consistent if not efficient estimates. Given that we are not concerned with the efficiency of the individual parameter estimates in the VAR (we use LASSO to improve the efficiency of the system) this problem is less pressing. It does, however, provide a further

\footnotetext{
${ }^{16}$ Recent work by Pesaran and Yang (2016) shows how a network can be characterized by $\delta_{i}$, the estimated degree of pervasiveness, based on the weighted column sums of the adjacency matrix (normalized by row). The most dominant node in the network has the largest value of $\delta_{i}$, subject to the caveat that $\delta_{i} \geqslant 0.5$ for the existence of a valid network effect. The application of this framework to our network provides evidence of weakly dominant banking and insurance sectors in the first phase and weakly dominant banking in the following two phases. None of the sovereign nodes become dominant in any phase. Consequently, the results of this approach are aligned with the results presented in the paper.
} 
rationale for favoring a $\operatorname{VAR}(2)$ specification over a higher order lag.

\subsubsection{Random ordering}

The weights of the networks discussed in the previous section are obtained from the variance decompositions, which are sensitive to the ordering of variables in a VAR. Chan-Lau (2017) provides evidence of this effect in financial networks and suggests alternatives. To check if our empirical results are sensitive to different orderings we reproduce the results presented in Table 5 using the random variable sequences of Klossner and Wagner (2014). This procedure permits calculation of the spillover index's maximum, minimum and standard deviation over different orderings.

Table 6 presents the results of random ordering exercise for the combined network. Comparing Tables 5 and 6 shows that the estimated average strength of links is not sensitive to various ordering. All estimates lie in the range (difference between minimum and maximum) and standard deviations in Phases 1-3 are more than 5 times smaller than the values of average strength. Completeness (the bottom panel of Table 6) is also estimated within the range with the smallest standard deviation in Phase 2 .

\subsubsection{Omitted common exogenous factors}

Panel A of Table 7 gives the results for when the network is estimated without the inclusion of the exogenous common controls, $\mathrm{Exo}_{t}$ in equation (3). While the average strength of the links is only marginally changed the model with no common exogenous variables has an increased number of edges and consequently an increased weighted completeness. The most evident difference is in the number of edges and the strength of these edges during the GFC (Phase 2) - without taking into account the exogenous variables these statistics estimates 4345 edges compared with 3737 edges with controls and the average strength is 0.0104 compared to 0.0093 . Incorporating the exogenous factors into the model reduces the number of links established between Phase 1 and 2 to 3153 compared with 3599 links when we ignore changes in the external economic environment. 
The results support arguments made in the literature that ignoring common factors will lead to an over-estimation of the degree of interconnectedness in a network.

\subsubsection{GARCH filtered returns}

A number of existing papers pre-filter data for $\operatorname{GARCH}(1,1)$ prior to network estimation, including Billio et al. (2012), and Merton et al. (2013). The rationale behind this approach is that the volatility changes may result in over-identification of spillovers in levels. Our approach has been to retain the volatility as an important part of understanding the changing transmission process. We construct our estimates for the network using data prefiltered for $\operatorname{GARCH}(1,1)$ and report the results for the numbers of links, average strength of links and completeness statistics as before. The changes are not dramatic, and the qualitative story is unchanged. Panel B of Table 7 shows that weighted completeness increases marginally in Phase 1, the least volatile period, due to an increased number of identified links - the weight of the links is virtually unchanged between the filtered and unfiltered network. The number of links which are removed in the transition from Phase 1 to Phase 2 is larger, meaning that the drop in completeness is larger in the filtered model. The difference between the Phase 2 weighted completeness results is less than 0.01 using the filtered and unfiltered data. Essentially, there is no evidence that the filtering has any substantial effect on the results presented in the main body of the text (although in Billio et al., 2012, it eases the estimation problem).

\subsubsection{Other weight structures}

The choice of data to estimate weight structures will influence the outcome of the network linkages. When the weight structures change significantly the analytical results will be affected. Rather than iterating through many possible alternatives, some of which may be substitutes and some complements to the risk

premia revealed by CDS market linkages, the next steps in this agenda will be to construct multi-layer networks which allow for connections through different 
types of links. Research in this direction has recently emerged in Aldosoro and Alves (2017) who breakdown their network based on the asset class and long, medium or short term liabilities, and in Magkonis and Tsopanakis (2018) who combine the cross-country and inter-country linkages between equity, bond, and money markets for a subset of Eurozone countries.

\section{Robustness and Fragility: How the network re- acts to shocks}

We now consider the evidence for whether the network is robust-but-fragile, and how this might change during different phases of the sample we have examined. Thus far we have found that the network changes over time both in the number and strength of the links, providing evidence of contagion between phases, see also Betza et al. (2016). On top of this we now show that when the networks are faced with varying strengths and sources of shock they experience different rates of CDS default during the different phases.

We subject the networks in each phase to a range of shocks. The expected number of defaults can be estimated from significant Granger causality linkages and the respective variance decompositions, as discussed in Section 4. We assume that a higher number of expected CDS defaults in a network indicates a higher degree of fragility (Zhou, 2016). For any given network structure the estimated expected number of defaults is characterized by an external shock obtained as a standard deviation of an equally weighted portfolio of log-returns estimated from the exogenous variables discussed in Section 4, generated relative to the shock $V_{i j}$, and by the probability of a default for sovereign and financial sectors.

To estimate the probability of a default the predicted values of the CDS spreads from the estimates from equation (3) are used to generate one-step ahead forecasts. An expanding window forecasting is used to obtain the predicted sample of the CDS spreads in each of the phases. We count the number of days when a predicted spread is higher/lower than average CDS spreads. Formally, 
in each phase, the probability of a default for sector $K=$ (Sovereigns, Financial Institutions $)=(S, F)$ is given by

$$
\operatorname{Pr}^{\text {default }}(K)=\frac{\text { predicted number of increased CDS spreads }}{\text { number of days in a phase }}
$$

and

$$
\operatorname{Pr}^{\text {no default }}(K)=\frac{\text { predicted number of non-increased spreads }}{\text { number of days in a phase }} .
$$

These default probabilities are then combined together with the effect of the external shocks in each sector to obtain an aggregated shock, $u_{j, m}, j=1, \ldots, 107$, $m=1, \ldots, 4$ that affects each node $j$ (which is either a sovereign or a financial institution) subject to scenario $m$ :

Good times: $\quad u_{j, 1}=\operatorname{Pr}^{\text {no default }}(S) \cdot u_{j, 1}(S)+\operatorname{Pr}^{\text {no default }}(F) \cdot u_{j, 1}(F)$,

Stress : $\quad u_{j, 2}=\operatorname{Pr}^{\text {default }}(S) \cdot u_{j, 2}(S)+\operatorname{Pr}^{\text {default }}(F) \cdot u_{j, 2}(F)$,

Poor investment: $\quad u_{j, 3}=\operatorname{Pr}^{\text {no default }}(S) \cdot u_{j, 3}(S)+\operatorname{Pr}^{\text {default }}(F) \cdot u_{j, 3}(F)$,

Poor government: $\quad u_{j, 4}=\operatorname{Pr}^{\text {default }}(S) \cdot u_{j, 4}(S)+\operatorname{Pr}^{\text {no default }}(F) \cdot u_{j, 4}(F)$,

where $u_{j, m}(K)$ is an external shock obtained from $V_{i j}$ and the exogenous variables. These aggregated shocks are used to obtain variance decompositions for each entity. The total expected number of defaults for the entire network is given as the average of the variance decomposition elements related to the sovereign and financial institution nodes.

Figure 5 has three panels, representing how the network responds to shocks in the three different phases. Increases across the horizontal axis refer to higher volatility shocks, and indicate that even within the same network structure the expected rate of CDS default increases with higher volatility. That is, even interdependence may cause problems for financial networks during times of financial stress, stemming from mechanisms such as the flight to familiarity effect identified in Giannetti and Laeven $(2012,2015)$. These results confirm that each these highly interconnected networks display a structure with increasing fragility as volatility rises.

When the network structures change between the Phases, the diagrams also show changes in the default rates when faced with shocks, consistent with a 
changing degree of fragility in the network. Consider Phase 1. In this case the good times scenario where no shocks are applied, leads to an expected 2 defaults as volatility rises, even with high volatility of 3 standard deviation shocks. The case with shocks to the sovereigns (poor government) increases default probability only slightly. However, shocks through the financial sector (poor investment) promote more fragility. Up to 15 defaults may be observed in the financial sector in response to 3 standard deviation financial sector shocks. In combination, where both sovereign and financial sector shocks occur (crisis times) the increase is only slightly above that of poor investment. Here the main source of fragility is clearly in the financial sector.

Phase 2, the crisis period, provides a different picture. Even in the no shock scenario (good times) the network is fragile in response to high volatility. With high volatility over 60 of the 107 nodes are expected to default. With the addition of sovereign and financial sector induced shocks, this rises to over 100, or almost all the nodes. (This means that mechanisms which transfer shocks in one sector to the other must be in place, as the expected number of defaults exceeds the number of nodes in either sector.)

In response to shocks and periods of increased volatility the network is highly fragile in Phase 2. It is evident that the main source of the volatility in this phase is via the sovereign debt market. This likely reflects the many programs put in place to support the banking sector during this phase, which resulted in risk transfer from the banking sector in Phase 1 to the sovereign sector in Phase 2 .

In Phase 3 the results support a robust network. The expected number of defaults reduces considerably. The probability of default when not subject to shocks but facing rising volatility (good times) is similar to Phase 1. However, the overall expected number of defaults when faced with shocks from both sectors (stress) is vastly reduced over Phase 1, with fewer than 4 defaults expected even under high volatility conditions. Further, the expected defaults from shocks sourced in either sovereign or financial sector separately now have similar effects in producing defaults. 
These scenarios present a convincing anatomy of the crisis and serve to confirm that not only is a robust-but-fragile structure supported in the data, but that the fragility of the network changes across different phases. In the build up to the GFC the network was robust to increasing volatility, as long as there were not shocks to the increasingly fragile banking sector. The shift in network structure during the GFC crisis period presented a highly fragile network. During this period shocks to financial or sovereign sector nodes affected more than their own sector, with evidence that fragility had been effectively transferred to the sovereign sector. In the post-GFC phase the network returned to a more robust structure, despite the problems of the Greek and European debt crisis contained within the Phase, with more balance between the risk of default posed by either financial sector or sovereign sector shocks.

\section{Conclusion}

This paper investigates international connections between financial institutions and sovereign debt markets. The results reinforce the 'robust-but-fragile' nature of networks of financial institutions and sovereign debt markets where shocks from the credit provision decisions of either or both of these sources provide a means of amplifying uncertainty via the network. We analyze a panel of 107 financial institution and sovereign CDS spreads for the period 2003-2014. Within this period we identify three Phases which broadly correspond to the preGFC, GFC and a post-GFC period which incorporates the Greek and European debt crises.

The results of this work suggest that it is the intertwining of these markets that can result in financial fragility. In Phase 1 we observed a financial sector presenting important source of risk to the network robustness. While in Phase 2 the network is simply fragile to shocks sourced from either sector, the sovereign sector is a more important impetus for default. Finally Phase 3 shows the re-establishment of a more robust network, and one where the default risk from shocks in either sector is more equally aligned. The results support the 
importance of adopting a combined approach to systemic risk, monitoring both financial institution and sovereign debt. Transfer of risk from one sector to another, particularly during periods of stress, warrants vigilance in understanding which sector is the more vulnerable as the network changes over time.

The empirical work in this paper provides evidence of the changing strength of linkages between nodes in the network of financial institutions and sovereigns during periods of stress. The number of links between nodes changes between Phases 1 and 2, increasing the density of the unweighted combined network consistent with the existing literature. However, with a weighted network we find that weighted completeness can decrease during periods of stress due to the changing nature of the links. We demonstrate the effect of the case where the net number of connections increases, but with a reduction in the average strength of those connections. The number of stronger connections may reduce and more weaker connections emerge across Phases. The changing completeness of the combined network in the different phases and under different scenarios represents changes in the structure and combination of what Acemoglu et al. (2015) classify as a $\gamma$-convex combination of networks. Overall, less diversified patterns of linkages are more fragile during crisis times but could be more robust when normal times prevail.

Network analysis can considerably enrich our understanding of fragility in the financial sector. However, the tool requires a clear understanding of the components of the network, and how they change over time. On the one hand the unweighted network shows an increase in interconnectedness over time which under BIS criteria is indicative of more risk. On the other hand, the replacement of lost strong links with a larger number of weaker links is evidence that there are substitution possibilities in the network, pointing to a mechanism which aids in managing systemic risk. The results are clear that during Phase 2 , the GFC period, the network is more fragile than in the pre and post-GFC periods. The source of network fragility in the pre-GFC period is the financial sector, and the crisis results in feedbacks between banking and sovereign nodes consistent with the diabolic loop, while post-crisis the risks from sovereign and 
financial institution sourced shocks are more similar and the network is more robust.

\section{References}

[1] Acemoglu, D. Ozdaglar, A. and Tahbaz-Salehi, A. (2015) "Systemic risk and stability in financial networks", American Economic Review, 105, 564608.

[2] Acharya, V., Drechsler, I. and Schnabl, P. (2014a) "A pyrrhic victory? Bank bailouts and sovereign credit risk", Journal of Finance, 69, 2689-2739.

[3] Acharya, V., and Richardson, M. (2014b) "Is the insurance industry systemically risky?" in Biggs, J.H. and Richardson, M. (eds) Modernizing Insurance Regulation, New Jersey, Wiley, pp.151-179.

[4] Acharya, V. and Steffen, S. (2015) "The greatest carry trade ever? Understanding eurozone bank risks", Journal of Financial Economics, 115, 215-236.

[5] Alatavia, Pagano and Manganelli (2017) "Bank exposures and sovereign transmissions", Review of Finance, 21, 2103-2139.

[6] Aldosoro and Alves, I. (2017) "Multiplex interbank networks and systemic importance - An application to European data", BIS Working Paper 603.

[7] Allen, F. and Babus, A. (2009) "Networks in Finance", in Kleindorfer, P. and Wind, Y.(eds) "The network challenge: strategy, profit, and risk in an interlinked world" 367-382.

[8] Alter, A. and Beyer, A. (2014) "The dynamics of spillover effects during the European sovereign debt turmoil", Journal of Banking and Finance, $42,134-153$. 
[9] Alter, A. and Schuler, Y.S. (2012) "Credit spread interdependencies of European states and banks during the financial crisis", Journal of Banking and Finance, 36, 3444-3468.

[10] Anufriev, M. and Panchenko, V. (2015) "Connecting the dots: Econometric methods for uncovering networks with an application to the Australian financial institutions", Journal of Banking and Finance, 61, S241-S255.

[11] Arezki, R. Candelon, B., and Sy, A. (2011) "Sovereign rating news and financial market spillovers: Evidence from the European debt crisis", IMF Working Paper 11/68.

[12] Atil, A., Bradford, M., Elmarzougui, A., and Lahiani, A. (2016) "Conditional dependence of US and EU sovereign CDS: A time-varying copula based estimation", Finance Research Letters, 19, 42-53.

[13] Beck, T., Demirgüç-Kunt, A. and Levine, R. (2006) "Bank concentration, competition, and crises: First results", Journal of Banking and Finance, 30, 1581-1603.

[14] Bekaert, G. Ehrmann, M. Fratzscher, M. and Mehl, A. J. (2014) "The global crises and equity market contagion", The Journal of Finance, 69, 2597-2649.

[15] Betza, F., Hautsch, N., Peltonend, T. and Schienle, M. (2016) "Systemic risk spillovers in the European banking and sovereign network", The Journal of Financial Stability, 25, 206-224.

[16] Biggs J.H. and Richardson, M.(eds) (2014) Modernizing insurance regulation. New Jersey. Wiley.

[17] Billio, M., Casarin, R., Costola, M., and Psqualini, A. (2016) "An entropybased early warning indicator for systemic risk", Journal of International Financial Markets, Institutions and Money, 45, 42-59. 
[18] Billio, M., Getmansky, M., Lo, A. and Pelizzon, L. (2012) "Econometric measures of connectedness and systemic risk in the finance and insurance sectors", Journal of Financial Economics, 104, 535-559.

[19] Black, L., Correa, R., Huang, X. and Zhou, H.(2016) "The systemic risk of European banks during the financial and sovereign debt crises", Journal of Banking and Finance, 63, 107-125.

[20] Boyson, N.M. Stahel, C.W. and Stulz, R.M. (2010) "Hedge fund contagion and liquidity shocks", The Journal of Finance, 65, 1789-1816.

[21] Bouri, E., de Boyrie, M. and Pavlova, I. (2017) "Volatility transmission from commodity markets to sovereign CDS spreads in emerging and frontier countries", International Review of Financial Analysis, 65, 1789-1816.

[22] Brunnermeier, M., Garciano, C., Lane, P.R., Pagano, M., Reis, R., Santos, T., Thesmar, D., Van Nieuwerburg, S., and Vayanos, D. (2016) "Breaking the sovereign bank diabolic loop: The case for ESBies", American Economic Review Papers and Proceedings, 106, 1-8.

[23] Brunnermeier, M., Langfield, S., Pagano, M., Reis, R., Van Nieuwerburg, S., and Vayanos, D. (2017) "ESBies: Safety in the tranches", Economic Policy, 32, 175-219.

[24] Buch, C., Koettera, M., and Ohlsa, J. (2016) "Banks and sovereign risk: A granular view", Journal of Financial Stability, 25, 1-15.

[25] Busetti, F. and Harvey, A. (2011) "When is a copula constant? A test for changing relationships", Journal of Financial Econometrics, 49, 155-165.

[26] Caballero, J. (2015) "Banking crises and financial integration: Insights from networks science", Journal of International Financial Markets, Institutions and Money, 34, 127-146.

[27] Caporin, M., Pelizzon, L., Ravazzolo, F. and Rigobon, R. (2018) "Measuring sovereign contagion in Europe", Journal of Financial Stability, 34, 150-181. 
[28] Chan-Lau, J. (2017) "Variance decomposition networks: Potential pitfalls and a simple solution", IMF Working Paper 17/107.

[29] Chiaramonte, L. and Casu, B. (2012) "The determinants of bank CDS spreads. Evidence from the financial crisis", European Journal of Finance, $19,861-887$.

[30] Cummins, J.D. and Weiss, M.A. (2014) "Systemic risk and the US insurance sector", Journal of Risk and Insurance, 81, 489-528.

[31] De Bruyckere, V., Gerhardt, M., Schepens, G. and Vander Vennet, R. (2013) "Bank/sovereign risk spillovers in the European debt crisis", Journal of Banking and Finance, 37, 4793-4809.

[32] Demirer, M. Diebold, F.X. Liu, L. and Yilmaz, K. (2018) "Estimating global bank network connectedness", Journal of Applied Econometrics, 33, $1-15$.

[33] Diamond, P.A. (1982) "Aggregate demand management in search equilibrium", The Journal of Political Economy, 90, 881-894.

[34] Diebold, F.X. and Yilmaz, K. (2009) "Measuring financial asset return and volatility spillovers, with application to global equity markets", The Economic Journal, 119, 158-171.

[35] Diebold, F. and Yilmaz, K. (2014) "On the network topology of variance decompositions: measuring the connectedness of financial firms", Journal of Econometrics, 182, 119-134.

[36] Diebold, F. and Yilmaz, K. (2016) "Trans-Atlantic equity volatility connectedness: US and European financial institutions, 2004-2014", Journal of Financial Econometrics, 14, 81-127.

[37] Duca, M.L. and Peltonen, T.A. (2013) "Assessing systemic risks and predicting systemic events", Journal of Banking and Finance, 37, 2183-2195. 
[38] Dungey, M., Fry, R. Gonzalez-Hermosillo, B. and Martin, V.L. (2005) "Empirical modelling of contagion: a review of methodologies", Quantitative Finance, 5, 9-24.

[39] Dungey, M., Luciania, M., and Veredas, D. (2018) "Systemic risk in the US: Interconnectedness as a circuit breaker", Economic Modelling, 71, 305-315.

[40] Dungey, M. and Martin, V.L. (2007) "Unravelling financial market linkages during crises", Journal of Applied Econometrics, 22, 89-119.

[41] Dungey, M. Milunovich, G. Thorp, S. and Yang, M. (2015) "Endogenous crisis dating and contagion using smooth transition structural GARCH", Journal of Banking and Finance, 58, 71-79.

[42] Dungey, M. and Renault, E. (2018) "Identifying Contagion", Journal of Applied Econometrics, 33, 227-250.

[43] Eichengreen, B. Mody, A. Nedeljkovic, M. and Sarno, L. (2012) "How the subprime crisis went global: evidence from bank default swap spreads", Journal of International Money and Finance, 31, 1299-1318.

[44] Eom, C. and Park, J.W. (2014) "Effects of common factors on stock correlation networks and portfolio diversification", International Review of Financial Analysis, 49, 1-11.

[45] Fabozzi, F. Giacometti, R. and Tsuchida, N. (2016) "Factor decomposition of the Eurozone sovereign CDS spreads", Journal of International Money and Finance, 65, 1-23.

[46] Gai, P. and Kapadia, S. (2010) "Contagion in financial networks", Proceedings of the Royal Society of London A: Mathematical, Physical and Engineering Sciences, 383.

[47] Gianetti, M. and Laeven, L. (2012) "The flight home effect: Evidence from the syndicated loan market during financial crises", Journal of Financial Economics, 104, 23-43. 
[48] Gianetti, M. and Laeven, L. (2016) "Local ownership, crises, and asset prices: Evidence from US mutual funds", Review of Finance, 20, 947-978.

[49] Giraitis, L., Kapetanois, G., Wetherilt, A. and Zikes, F. (2016) "Estimating the dynamics and persistence of financial networks, with an application to the sterling money", Journal of Applied Econometrics, 31, 58-84.

[50] Glasserman, P. and Young, H.P. (2015) "How likely is contagion in financial networks?", Journal of Banking and Finance, 50, 383-399.

[51] Haldane, A.G. (2009) "Why banks failed the stress test", speech at the Marcus-Evans Conference on Stress-Testing, London, 9-10 February 2009.

[52] Hannoun, H. (2011) "Sovereign risk in bank regulation and supervision: where do we stand?" Address to Financial Stability Institute High-Level Meeting, Abu Dhabi, UAE, 26 October 2011

[53] Hastie, T., Tibshirani, R., Wainwright, M. (2015). Statistical Learning with Sparsity. New York: Chapman and Hall.

[54] Jorda, O., Schularick, M., and Taylor, A.M. (2016) "Sovereigns versus banks: Credit, crises and consequences" Journal of the European Economic Association, 14, 45-79.

[55] Kalbaska, A. and Gatkowsi, M. (2012) "Eurozone sovereign contagion: Evidence from the CDS market (2005-2010)", Journal of Economic Behavior and Organization, 83, 657-673.

[56] Kallestrup, R., Lando, D. and Murgoci, A. (2016) "Financial sector linkages and the dynamics of bank and sovereign spreads", Journal of Empirical Finance, 38 part A, 374-393.

[57] Klossner, S. and Wagner, S. (2014) "Exploring all VAR orderings for calculating spillovers? yes, we can - a note on Diebold and Yilmaz (2009)", Journal of Applied Econometrics 29, 172-179. 
[58] Koop, G. Pesaran, M.H. and Potter, S.M. (1996) "Impulse response analysis in nonlinear multivariate models", Journal of Econometrics, 74, 119-147.

[59] Korte, J. and Steffen, S. (2017) "The zero risk fallacy - banks' sovereign exposure and sovereign risk spillovers", manuscript.

[60] Liao, Z. and Phillips, P.C.B. (2015) "Automated estimation of vector error correction models", Econometric Theory, 31, 581-646.

[61] Longstaff, F.A. (2010) "The subprime credit crisis and contagion in financial markets", Journal of Financial Economics, 97, 436-450.

[62] Longstaff, F.A., Pan, J., Pedersen, L.H. and Singleton, K.J. (2011) "How sovereign is sovereign credit risk?", American Economic Journal: Macroeconomics, 3, 75-103.

[63] Magkonis, G. and Tsopanakis, A. (2018) "The financial connectedness between Eurozone core and periphery: A disaggregated view", manuscript.

[64] Marais, E. and Bates, S. (2006) "An empirical study to identify shift contagion during the Asian crisis", Journal of International Financial Markets, Institutions and Money, 16, 468-479.

[65] Merton, R.C. Billio, M. Getmansky, M. Gray, D. Lo, A. W. and Pelizzon, L. (2013) "On a new approach for analyzing and managing macrofinancial risks", Financial Analysts Journal, 69, 22-33.

[66] Onega, S., Popov, A. and van Horen, N. (2016) "The invisible hand of government: Moral suasion during the European sovereign debt crisis", ECB working paper no. 1937.

[67] Pan, J. and Singleton, K.J. (2008) "Default and recovery implicit in the term structure of sovereign CDS spreads", The Journal of Finance, 63, 2345-2384.

[68] Pesaran, M.H. and Shin, Y. (1998) "Generalized impulse response analysis in linear multivariate models", Economics Letters, 58, 17-29. 
[69] Pesaran, M.H., and Yang, C. (2016) "Econometric analysis of production networks with dominant units", USC Dornsife Institute for New Economic Thinking Working paper No. 16-25.

[70] Podstawski, M. and Velinov, A. (2018) "The state dependent impact of bank exposure on sovereign", Journal of Banking and Finance, 88, 63-75.

[71] Reinhart, C. and Rogoff, K. (2009) This Time is Different: Eight Centuries of Financial Folly, Princeton, Princeton University Press.

[72] Sander, H. and Kleimeier, S. (2003) "Contagion and Causality: an empirical analysis of four Asian crisis episodes", Journal of International Financial Markets, Institutions and Money, 13, 171-186.

[73] Scida, D. (2015) "Structural VAR and financial networks: a minimum distance approach to spatial modeling", manuscript, Brown University.

[74] Ureche-Rangau, L. and Burietz, A. (2013) "One crisis, two crises...The subprime crisis and the European sovereign debt problems", Economic Modelling, 35, 35-44.

[75] van der Leur, M. and Lucas, A. (2017) "Network, market and book-based systemic risk rankings", Journal of Banking and Finance, 78, 84-90.

[76] Zhou, Z. (2016) "Systemic Bank Panics in Financial Networks", manuscript. 
Table 1: Financial institutions grouped by broad type.

\begin{tabular}{lll}
\hline \hline Banks & Financials & Insurance \\
\hline \hline Aust \& New Zld Bkg & ACOM CO LTD & ACE Ltd \\
Amern Express Co & John Deere Cap Corp & Aegon N.V. \\
Barclays Bk plc & MBIA Inc. & American Intl Gp Inc \\
BNP Paribas & Natl Rural Utils Coop & Allstate Corp \\
Cap One Finl Corp & Aiful Corp & Aon Corp \\
Citigroup Inc & ORIX Corp & Assicurazioni Generali \\
Ctrywde Home Lns & Gen Elec Cap Corp & CHUBB CORP \\
Kookmin Bk & Goldman Sachs Gp Inc & CNA Finl Corp \\
Commerzbank AG & Morgan Stanley & Legal \& Gen Gp PLC \\
Deutsche Bk AG & SEARS ROEBUCK & MBIA Ins Corp \\
Hana Bank & Toyota Mtr Cr Corp & MetLife Inc \\
HSBC Bk plc & Swire Pac Ltd & Munich Re \\
ING Bk N V & & Old Mut plc \\
Korea Dev Bk & & Safeco Corp \\
Merrill Lynch \& Co & & Mitsui Sumitomo Ins \\
Mizuho Corporate Bk & & Sompo Japan Ins Inc \\
Macquarie Bk Ltd & & HARTFORD FIN INC \\
Natl Aust Bk Ltd & & Loews Corp \\
Oversea Chinese Bkg & & \\
Rabobank Nederland & & \\
Royal Bk of Scotland & & \\
Resona Bk Ltd & & \\
Societe Generale & & \\
Std Chartered Bk & & \\
Sumitomo Mitsui Bkg & & \\
UBS AG & & \\
Wells Fargo \& Co & & \\
Westpac Bkg Corp & & \\
\hline \hline Investment & Real Estate & \\
\hline \hline Daiwa Secs Gp & EOP Oper Ltd Pship & \\
Bombardier & Hammerson PLC & \\
Nomura Secs & Hongkong Ld Co & \\
& Mitsubishi Estate Co & \\
& Simon Ppty Gp L P & \\
\hline
\end{tabular}


Table 2: Sovereigns grouped by region. Groups are intentionally broad to minimize the total number.

\begin{tabular}{lll}
\hline \hline Europe & Asia & Latin America \\
\hline \hline Bulgaria & Australia & Argentina \\
Czech Republic & China & Brazil \\
Denmark & Indonesia & Chile \\
Norway & Japan & Colombia \\
Poland & Malaysia & Mexico \\
Sweden & Philippines & Panama \\
Russia & South Korea & Peru \\
Turkey & Thailand & Venezuela \\
Ukraine & Vietnam & \\
& & \\
\hline \hline Africa & Euro Zone & North America \\
\hline \hline Israel & Belgium & USA \\
Morocco & Finland & \\
South Africa & France & \\
Qatar & Germany & \\
& Ireland & \\
& Italy & \\
& Netherlands & \\
& Portugal & \\
& Spain & \\
\hline
\end{tabular}


Table 3: Summary statistics are reported for sovereign and financial institution CDS spread data used in this paper.

\begin{tabular}{|c|c|c|c|c|c|}
\hline & Obs. & Mean & $\overline{\text { Std dev }}$ & Skewness & Kurtosis \\
\hline Phase 1 & \multicolumn{5}{|c|}{$01 / 01 / 2003-14 / 09 / 2008$} \\
\hline Banks & 1488 & 0.4253 & 0.6634 & 6.2252 & 73.1315 \\
\hline Financials & 1488 & 0.7426 & 1.4386 & 9.2843 & 131.738 \\
\hline Insurance & 1488 & 0.5413 & 1.1174 & 10.551 & 146.240 \\
\hline Investment & 1488 & 1.0126 & 1.6023 & 3.5076 & 19.9933 \\
\hline Real Estate & 1488 & 0.5737 & 0.5135 & 2.5807 & 11.3350 \\
\hline Latin America & 1488 & 3.3274 & 5.0302 & 4.3823 & 24.8403 \\
\hline Asia & 1488 & 1.0935 & 1.3470 & 1.4863 & 4.1704 \\
\hline Euro Zone & 1488 & 0.0698 & 0.0759 & 2.8669 & 11.6775 \\
\hline Europe & 1488 & 0.9062 & 1.5211 & 2.8717 & 13.9841 \\
\hline Africa & 1488 & 0.8038 & 0.7205 & 2.5980 & 11.9358 \\
\hline North America & 1488 & 0.0262 & 0.0311 & 2.9249 & 11.0294 \\
\hline Phase 2 & \multicolumn{5}{|c|}{$\overline{15 / 09 / 2008-31 / 03 / 2010}$} \\
\hline$\overline{B a n k s}$ & 403 & 1.6490 & 1.2574 & 2.1977 & 8.4938 \\
\hline Financials & 403 & 12.719 & 32.619 & 6.6554 & 58.383 \\
\hline Insurance & 403 & 3.6890 & 5.1029 & 2.4613 & 9.2081 \\
\hline Investment & 403 & 1.9650 & 1.1711 & 1.0721 & 2.8133 \\
\hline Real Estate & 403 & 2.6080 & 2.4492 & 1.4525 & 4.1223 \\
\hline Latin America & 403 & 6.3541 & 8.8135 & 2.2891 & 7.7371 \\
\hline Asia & 403 & 2.0159 & 1.5864 & 1.7696 & 7.0876 \\
\hline Euro Zone & 403 & 0.8250 & 0.5597 & 1.5966 & 6.8034 \\
\hline Europe & 403 & 3.4588 & 6.4693 & 3.8884 & 20.298 \\
\hline Africa & 403 & 1.9245 & 0.9750 & 1.3394 & 4.5551 \\
\hline North America & 404 & 0.4169 & 0.1834 & 1.1935 & 3.9374 \\
\hline Phase 3 & \multicolumn{5}{|c|}{$01 / 04 / 2010-21 / 10 / 2013$} \\
\hline Banks & 951 & 1.3971 & 0.6334 & 1.6584 & 6.8687 \\
\hline Financials & 951 & 6.3933 & 10.211 & 2.0464 & 5.9045 \\
\hline Insurance & 951 & 1.8314 & 2.1538 & 3.7857 & 20.033 \\
\hline Investment & 951 & 1.4738 & 1.0772 & 0.5886 & 2.2274 \\
\hline Real Estate & 951 & 1.1053 & 0.4586 & 0.6091 & 2.8172 \\
\hline Latin America & 951 & 3.7769 & 5.6733 & 3.1106 & 14.840 \\
\hline Asia & 951 & 1.3284 & 0.7275 & 1.6687 & 6.1909 \\
\hline Euro Zone & 951 & 2.5872 & 2.5487 & 1.9267 & 7.1373 \\
\hline Europe & 951 & 1.6592 & 1.9220 & 2.2460 & 7.9880 \\
\hline Africa & 951 & 1.4990 & 0.5059 & 0.5376 & 2.5000 \\
\hline North America & 951 & 0.3067 & 0.0801 & -0.2616 & 2.3762 \\
\hline
\end{tabular}


Table 4: Jaccard similarity coefficients $\left(J C_{i j}\right)$ are estimated for phases $i$ and $j$. The values significant at the $5 \%$ level are marked by $(*)$. If $J C_{i j}<0.5$ the hypothesis of equal connectedness in two phases is rejected.

\begin{tabular}{lll}
\hline \hline & $J C_{12}$ & $J C_{23}$ \\
\hline Financial network & $0.2531^{*}$ & $0.1877^{*}$ \\
\hline Combined network & $0.2135^{*}$ & $0.1724^{*}$ \\
\hline
\end{tabular}

Table 5: This table contains statistics used in the analysis of network structures.

The average link strength is estimated from the connectedness of each respective network. The number of edges was calculated using bivariate Granger causality tests between network nodes (entities). Completeness is calculated via equation (9).

\begin{tabular}{llllllll}
\hline \hline & & & \multicolumn{3}{c}{ Formed } & \multicolumn{2}{c}{ Removed } \\
\hline & Phase 1 & Phase 2 & Phase 3 & 1 to 2 & 2 to 3 & 1 to 2 & 2 to 3 \\
\hline Financial network & & & & & & & \\
\hline Average strength & 0.0203 & 0.0171 & 0.0188 & 0.0164 & 0.0185 & 0.0196 & 0.0172 \\
No. of edges & 1040 & 1323 & 563 & 1024 & 386 & 741 & 1146 \\
Completeness & 0.4125 & 0.3833 & 0.2000 & 0.2852 & 0.1348 & 0.2843 & 0.3356 \\
\hline Combined network & & & & & & & \\
\hline Average strength & 0.0137 & 0.0093 & 0.0124 & 0.0088 & 0.0123 & 0.0125 & 0.0092 \\
No. of edges & 1734 & 3737 & 1297 & 3153 & 863 & 1150 & 3303 \\
Completeness & 0.2828 & 0.3452 & 0.1764 & 0.2748 & 0.1161 & 0.1705 & 0.3018 \\
\hline
\end{tabular}

Table 6: This table contains statistics used in the analysis of network structures.

The average link strength is estimated from the connectedness of each respective network. The number of edges was calculated using bivariate Granger causality tests between network nodes (entities). Completeness is calculated via equation (9). Minimum, maximum and standard deviations of these statistics are obtained using random variable sequences following Klossner and Wagner (2014).

\begin{tabular}{lccccccc}
\hline \hline & & \multicolumn{4}{c}{ Formed } & \multicolumn{2}{c}{ Removed } \\
\hline & Phase 1 & Phase 2 & Phase 3 & 1 to 2 & 2 to 3 & 1 to 2 & 2 to 3 \\
\hline Combined network & & & & & & & \\
\hline Average strength & 0.0137 & 0.0093 & 0.0124 & 0.0088 & 0.0123 & 0.0125 & 0.0092 \\
Minimum & 0.0125 & 0.0090 & 0.0103 & 0.0087 & 0.0106 & 0.0124 & 0.0091 \\
Maximum & 0.0168 & 0.0105 & 0.0184 & 0.0106 & 0.0178 & 0.0168 & 0.0105 \\
Standard deviation & 0.0018 & 0.0001 & 0.0016 & 0.0001 & 0.0017 & 0.0018 & 0.0001 \\
\hline Completeness & 0.2828 & 0.3452 & 0.1764 & 0.2748 & 0.1161 & 0.1705 & 0.3018 \\
Minimum & 0.2656 & 0.3421 & 0.1516 & 0.2706 & 0.1027 & 0.1701 & 0.3004 \\
Maximum & 0.3557 & 0.4086 & 0.2722 & 0.3444 & 0.1707 & 0.2308 & 0.3585 \\
Standard deviation & 0.0370 & 0.0186 & 0.0231 & 0.0177 & 0.0163 & 0.0245 & 0.0171 \\
\hline
\end{tabular}


Table 7: Robustness results to networks estimated (A) without common exogenous factors and (B) with $\operatorname{GARCH}(1,1)$ pre-filtering. This table contains statistics used in the analysis of network structures. The average link strength is estimated from the connectedness of each respective network. The number of edges was calculated using Completeness is calculated via equation (9).

\begin{tabular}{llllllll}
\hline \hline & & & & \multicolumn{2}{c}{ Formed } & \multicolumn{2}{c}{ Removed } \\
\hline & Phase 1 & Phase 2 & Phase 3 & 1 to 2 & 2 to 3 & 1 to 2 & 2 to 3 \\
\hline $\begin{array}{l}\text { A: Without exogenous factors } \\
\text { Average strength }\end{array}$ & 0.0133 & 0.0104 & 0.0126 & 0.0100 & 0.0123 & 0.0106 & 0.0103 \\
No. of edges & 1889 & 4345 & 1552 & 3599 & 913 & 1143 & 3706 \\
Completeness & 0.3604 & 0.4579 & 0.2249 & 0.3642 & 0.1290 & 0.1746 & 0.3851 \\
\hline B: GARCH(1,1) prefiltering & & & & & & & \\
Average strength & 0.0131 & 0.0096 & 0.0103 & 0.0091 & 0.0103 & 0.0127 & 0.0097 \\
No. of edges & 1997 & 3567 & 1363 & 2882 & 904 & 1312 & 3108 \\
Completeness & 0.3359 & 0.3507 & 0.1572 & 0.2696 & 0.1043 & 0.2143 & 0.3094 \\
\hline
\end{tabular}




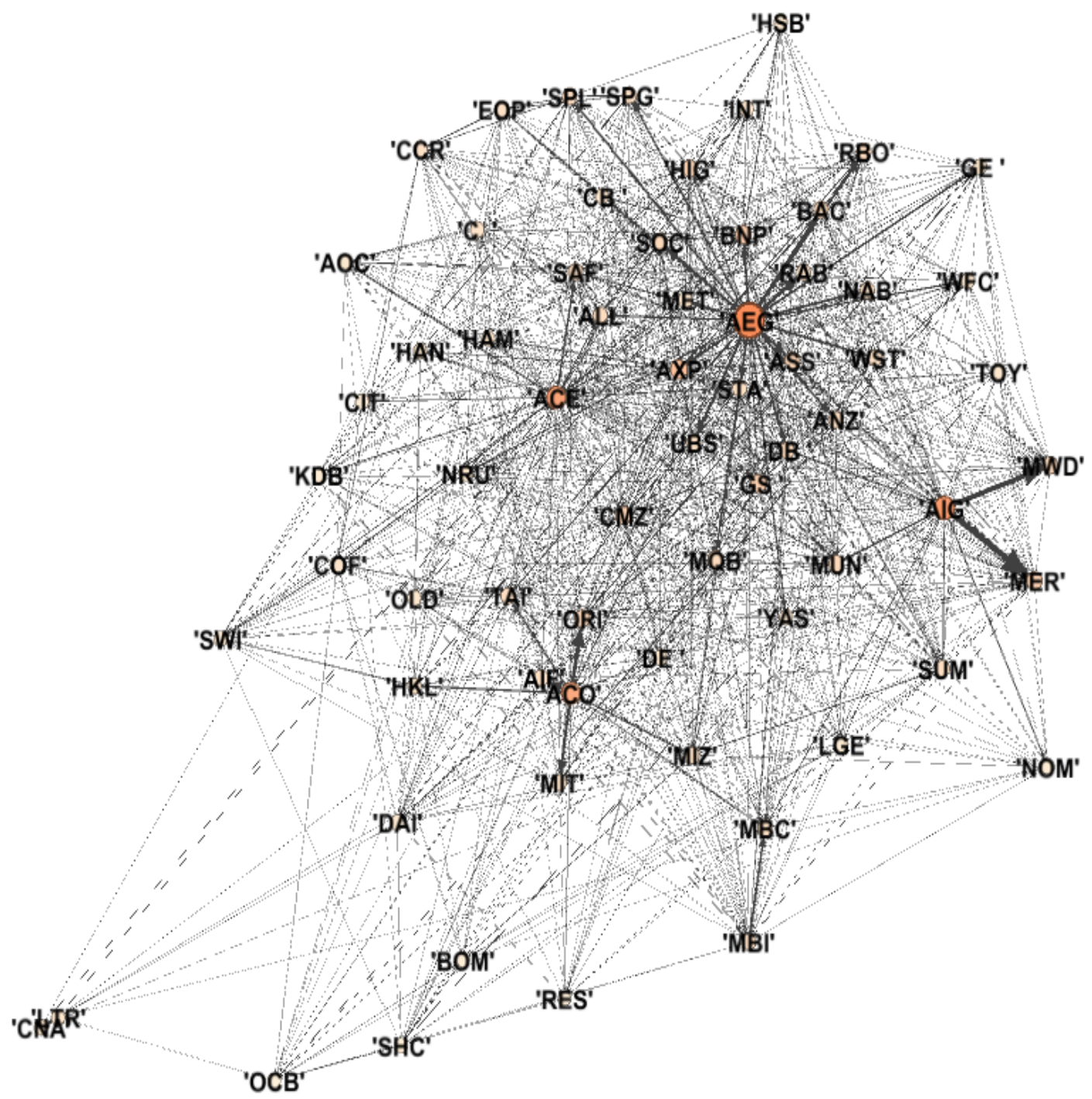

Figure 1: This figure displays the network of financial institutions in Phase 1 $(01 / 01 / 2003$ - 14/09/2008). Edges were calculated with Granger causality tests between financial institutions (nodes) at the $5 \%$ level of significance. 


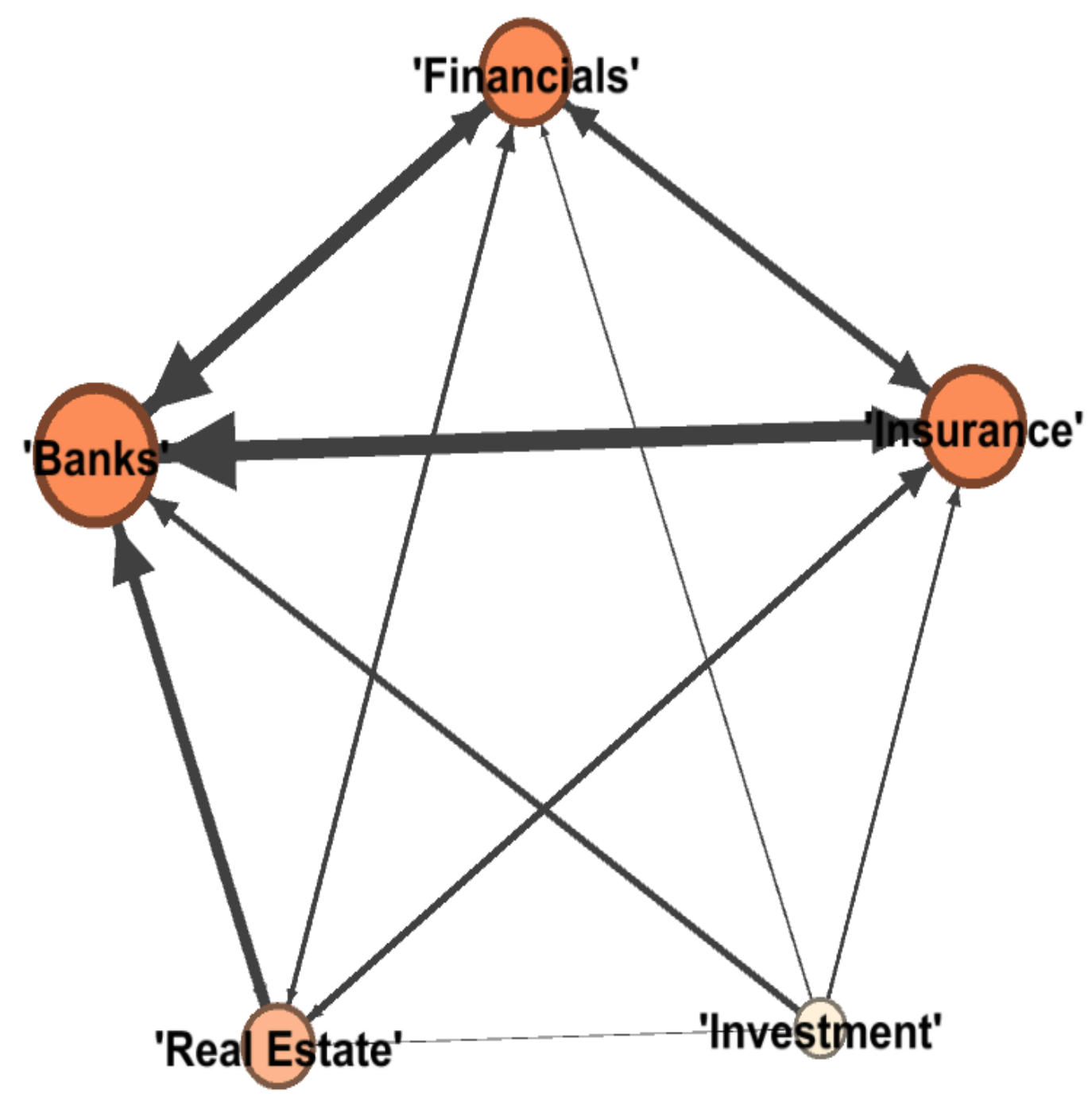

Figure 2: This figure shows a condensed version of the Phase 1 financial network from Figure 1. The changes are performed by grouping financial institutions/nodes into industries. 


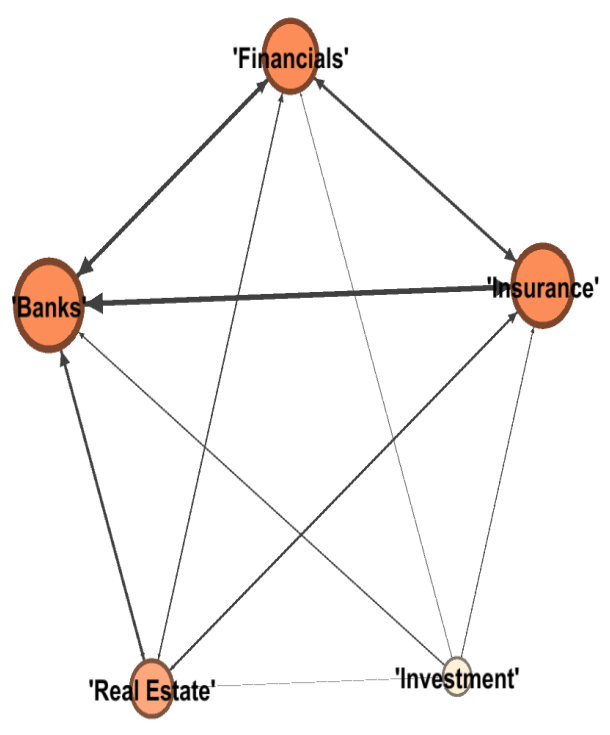

(a): Removed links Phase 1 to 2

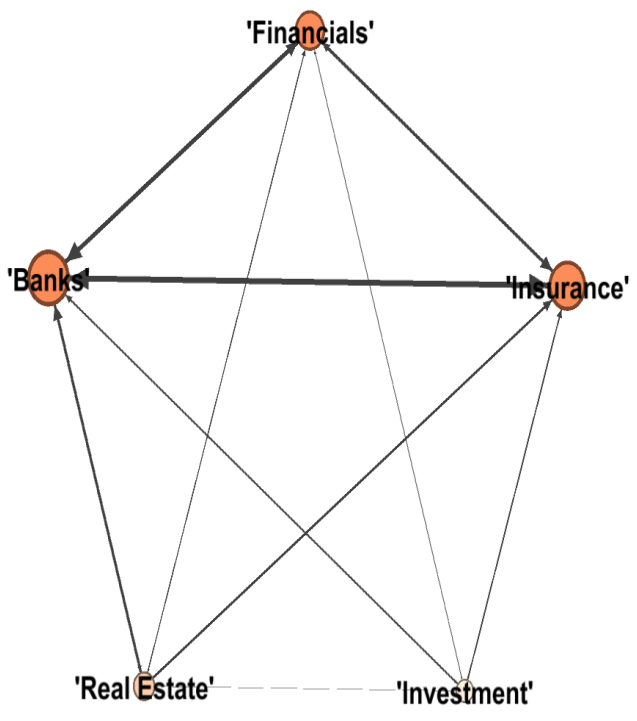

(c): Formed links Phase 1 to 2

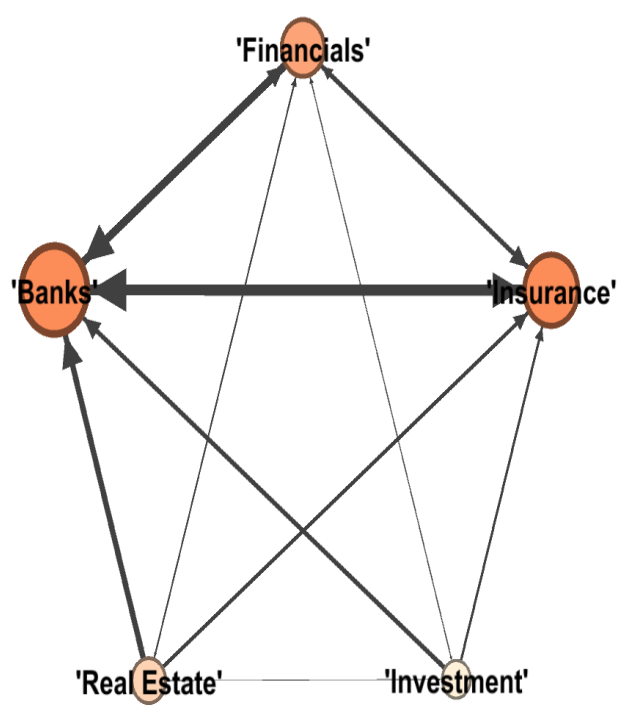

(b): Removed links Phase 2 to 3

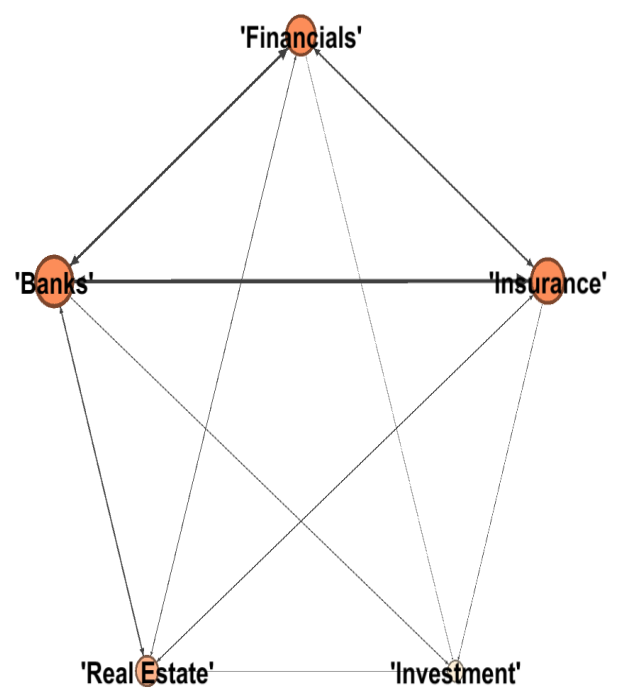

(d): Formed links Phase 2 to 3

Figure 3: This group of figures displays changes in the financial network between Phase 1 (01/01/2003 - 14/09/2008), Phase $2(15 / 09 / 2008$ - 31/03/2010) and Phase 3 $(01 / 04 / 2010-21 / 10 / 2013)$. Changes are calculated using matrix $\widetilde{A}$. 


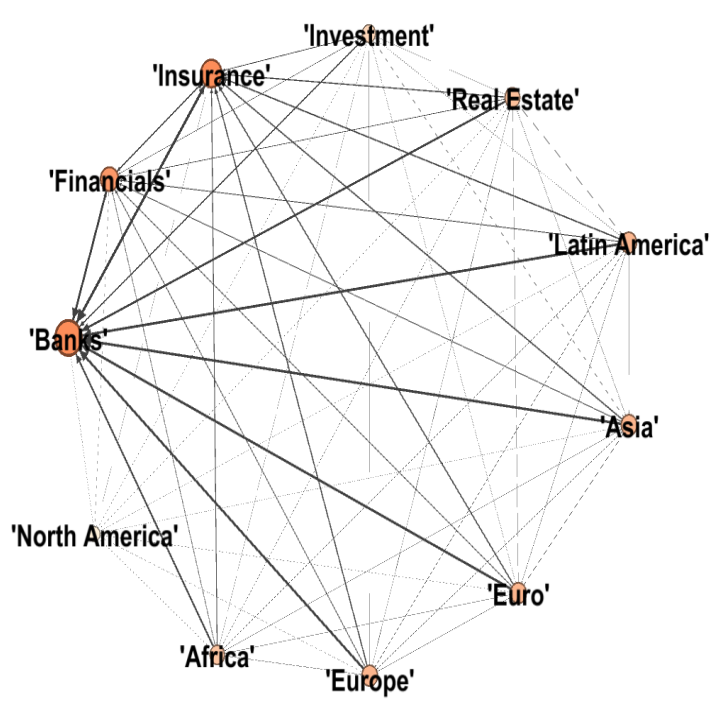

(a): Removed links Phase 1 to 2

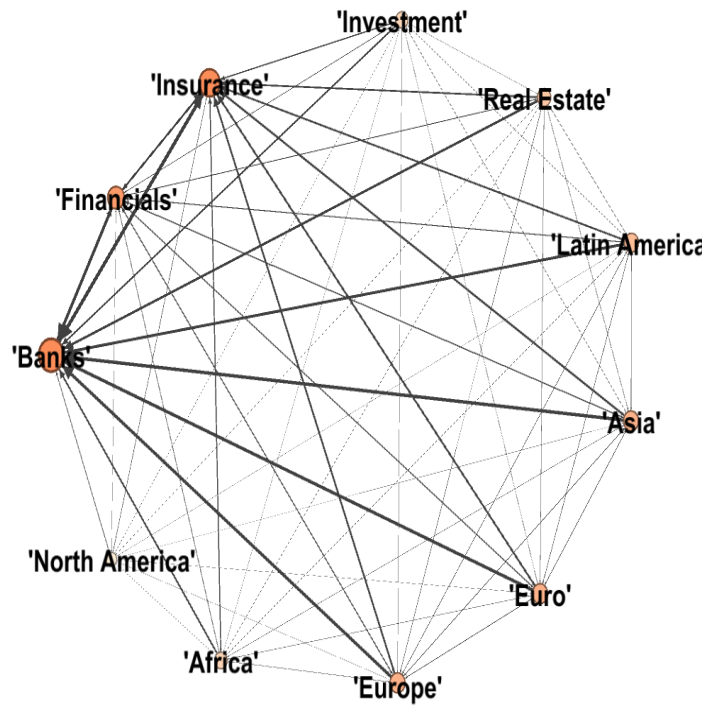

(c): Formed links Phase 1 to 2

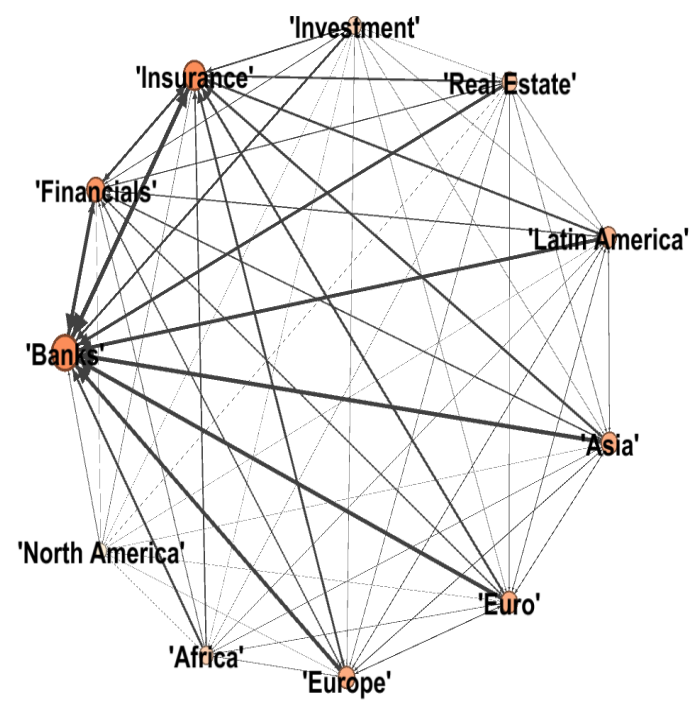

(b): Removed links Phase 2 to 3

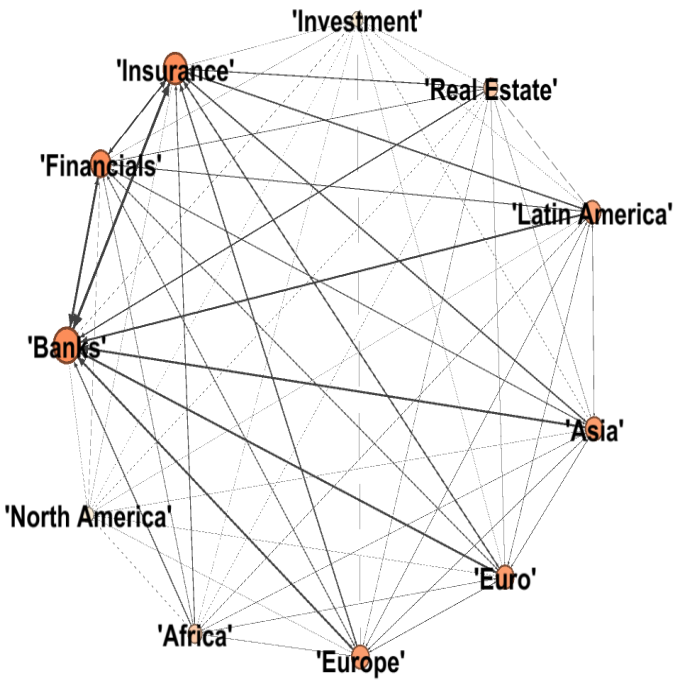

(d): Formed links Phase 2 to 3

Figure 4: This group of figures displays the combined sovereign and financial network changes. Changes between Phase $1(01 / 01 / 2003$ - 14/09/2008), Phase $2(15 / 09 / 2008-31 / 03 / 2010)$ and Phase $3(01 / 04 / 2010-21 / 10 / 2013)$ are calculated from matrix $\widetilde{A}$. 


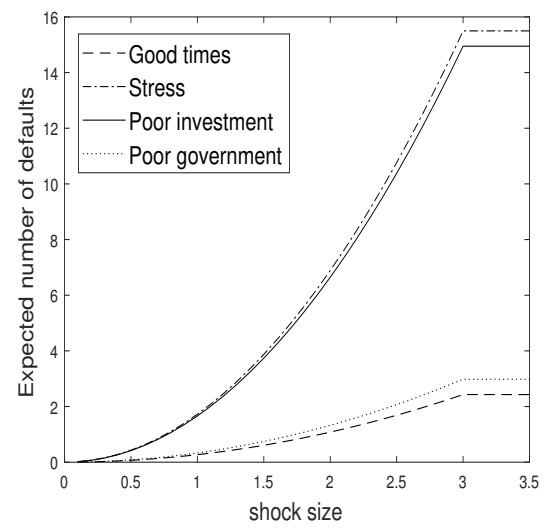

(a): Phase $1(01 / 01 / 2003-14 / 09 / 2008)$

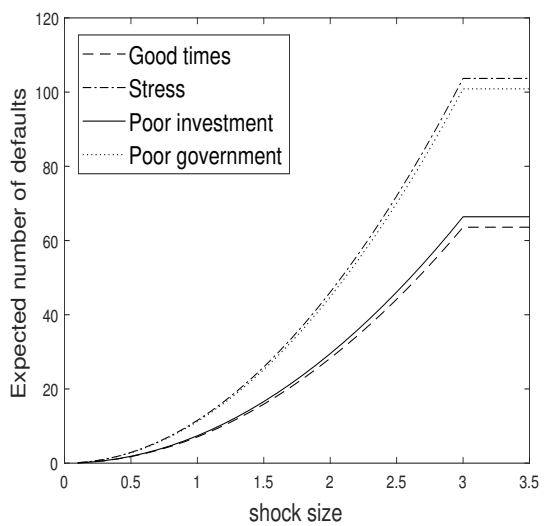

(b): Phase $2(15 / 09 / 2008-31 / 03 / 2010)$

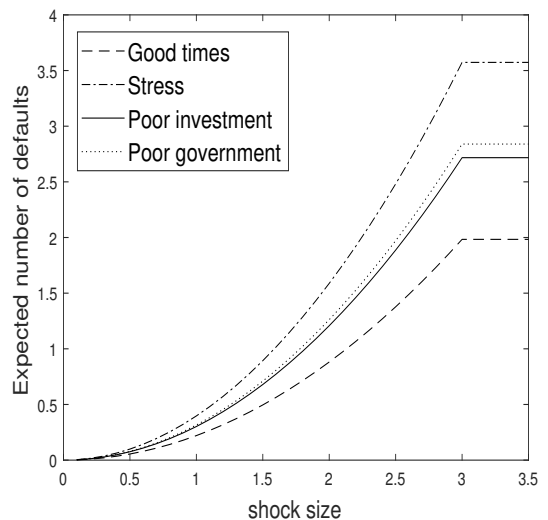

(c): Phase $3(01 / 04 / 2010-21 / 10 / 2013)$

Figure 5: This set of figures shows expected number of defaults in the combined network for a shock size by multiples of standard deviations under the different scenarios. The logarithm of the CDS spreads is used for calculation. 